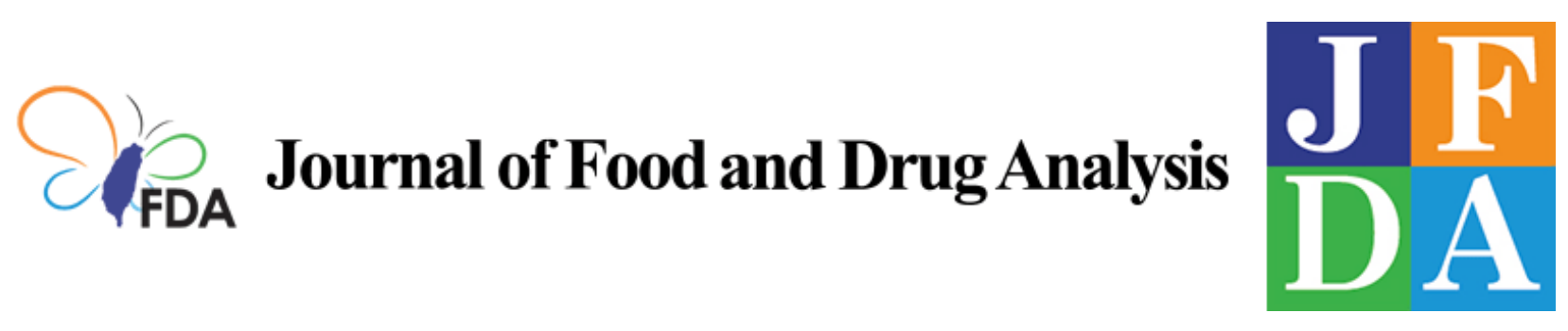

Volume 29 | Issue 2

Article 1

2021

\title{
Current and Potential Applications of Simultaneous DSC-FTIR Microspectroscopy for Pharmaceutical Analysis
}

Follow this and additional works at: https://www.jfda-online.com/journal

Part of the Food Science Commons, Medicinal Chemistry and Pharmaceutics Commons, Pharmacology Commons, and the Toxicology Commons

(c) (i) (8)

This work is licensed under a Creative Commons Attribution-Noncommercial-No Derivative Works 4.0 License.

\section{Recommended Citation}

Lin, Shan-Yang (2021) "Current and Potential Applications of Simultaneous DSC-FTIR Microspectroscopy for Pharmaceutical Analysis," Journal of Food and Drug Analysis: Vol. 29 : Iss. 2 , Article 1.

Available at: https://doi.org/10.38212/2224-6614.3345

This Review Article is brought to you for free and open access by Journal of Food and Drug Analysis. It has been accepted for inclusion in Journal of Food and Drug Analysis by an authorized editor of Journal of Food and Drug Analysis. 


\title{
Current and potential applications of simultaneous DSC-FTIR microspectroscopy for pharmaceutical analysis
}

\author{
Shan-Yang Lin
}

Laboratory of Pharmaceutics and Biopharmaceutics, Department of Biotechnology and Pharmaceutical Technology, Yuanpei University of Medical Technology, No. 306, Yuanpei Street, Hsinchu 30015, Taiwan

\begin{abstract}
Quality control (QC) is the most important key issue in the pharmaceutical industry to ensure the quality of drug products. Many analytical instruments and techniques in pharmaceutical analysis are applied to assess the quality and quantity of the drugs. In the current and future trends, a combination of digitization, automation and hyphenation with high throughput on-line performance will be the topics for the future of pharmaceutical QC. The hyphenated analytical techniques have recently received great attention as unique means to solve complex analytical problems in a short period of time. This review article is an update on the recent potential applications of hyphenated technique developed from the coupling of a rapid separation or induction technique (differential scanning calorimetry; DSC) and an on-line spectroscopic (Fourier transform infrared; FTIR) detection technology to carry out an one-step solid-state analysis in pharmaceutical formulation developments, including (1) intramolecular condensation of pharmaceutical polymers, (2) intramolecular cyclization of drugs and sweetener, (3) polymorphic transformation of drugs and excipients, (4) drugpolymer (excipient) interaction, (5) fast cocrystal screening and formation. This simultaneous DSC-FTIR microspectroscopy can also provide an easy and direct method for one-step screening and qualitative detection of drug stability in real time.
\end{abstract}

Keywords: DSC-FTIR microspectroscopy, Hyphenation, One-step, Real time, Solid-state analysis

\section{Introduction}

A ccording to the "Quality Guidelines" of ICH for the development of pharmaceutical drug products, understanding the physicochemical properties of active pharmaceutical ingredients (APIs) and excipients is an important prerequisite for successful development and manufacture of different dosage forms [1,2]. The physicochemical properties of both APIs and excipients include particle size, powder properties, moisture content, hygroscopicity, crystal properties, solubility, polymorphs, stability and their compatibility [3-5]. These properties play a crucial role in pharmaceutical development; it must pay more attention in the pharmaceutical manufacturing processes [6-9]. Moreover, several manufacturing factors such as temperature, light, humidity, pressure, processing time, and solvents used have found to influence the solid-state characteristics of APIs and excipients, leading to alterations of the physicochemical properties, bioavailability and therapeutic efficacy of the APIs [10-12].

From the ICH guidance and US FDA regulation for drug development and manufacturing, a detailed characterization of the critical physical attributes of the pharmaceutical materials should make sure to comply with regulatory requirements $[13,14]$. It has been known that the solid state characterization of pharmaceutical solids can be analyzed by several analytical techniques [15-21]. Brittain et al. classified the physical properties of 
Table 1. Classification of physical characterization of pharmaceutical solids by various analytical approaches [Modified, with permission from Ref. [15]].

\begin{tabular}{lll}
\hline Molecular level & Particulate level & Bulk level \\
\hline Spectroscopies & Spectroscopies & Micromeritics \\
Light Microscopy & Terahertz pulsed spectroscopy (TPS) & Powder characteristics tester \\
UV-vis spectroscopy (UV-VIS) & Terahertz Pulsed imaging (TPI) & - Angle of repose \\
Fluorescence spectroscopy & Fluorescence spectroscopy & - Cohesion \\
Fourier transform infrared spectroscopy (FTIR) & Dielectric spectroscopy & - Aerated density \\
Raman spectroscopy & X-ray photoelectron spectroscopy (XPS) & - Uniformity \\
Near-infrared spectroscopy (NIR) & Single-crystal X-ray diffraction (SCXRD) & - Dispersibility \\
Solid-state nuclear magnetic resonance & Particle morphology & Compressibility \\
spectrometry (SSNMR) & Polarized light microscopy (PLM) & Angle of Fall \\
& Scanning electron microscope (SEM) & Packed density \\
& Atomic force microscope (AFM) & - Angle of Spatula \\
& Transmission electron microscopy (TEM) & Angle of difference \\
& Particle size/distribution & Particle size \\
& Particle size analyzer & Powder flow analyzer \\
& Diffractometry & Gas pycnometry \\
& Powder $x$-ray diffraction (PXRD) & Moisture analyzer \\
& Thermal analysis & Wall friction tester \\
& Thermogravimetric analysis (TGA) Differential & Tensile tester \\
& scanning calorimetry (DSC) & Contact angle goniometer \\
& Modulated differential scanning calorimetry (MDSC) &
\end{tabular}

pharmaceutical solids into three main levels: (1) molecular level (properties associated with individual inorganic or organic molecules), (2) the particulate level (properties belonged to individual geometrical solid particles), and (3) the bulk level (properties associated with particulate assemblies) $[15,19]$. Table 1 lists the classification of physical characterization of pharmaceutical solids by various analytical approaches $[15,17,19]$, in which the molecular-level properties are usually evaluated by using vibrational spectroscopy and solid-state nuclear magnetic resonance spectrometry (SSNMR); the particulate level properties are determined by particle morphology, particle size/distribution, thermal and diffractometric methods; and the bulk level properties are focused on surface area, porosity and pore size distribution, and powder flow characteristics $[15,21-23]$.

Since many APIs can exist in different pharmaceutical solid forms, the solubility, flowability, compressibility, physical and chemical stability, and reactivity of these APIs may be altered depending on manufacturing processes and/or under storage conditions of the final solid dose forms. Scheme 1 illustrates the manufacturing processes affecting solid state characterization of drug substances. Therefore, selecting an optimal solid form of an API is of considerable importance and also a key factor to maintain the selected solid form through formulation development, scale up, manufacturing processes, storage and usage of drug products. Particularly, the possibility of compatibility/

\begin{tabular}{|c|c|c|c|}
\hline APIs & $\begin{array}{c}\text { Manufacturing } \\
\text { processes }\end{array}$ & $\begin{array}{l}\text { Powder/particle } \\
\text { characteristics }\end{array}$ & $\begin{array}{c}\text { Physicochemical } \\
\text { properties }\end{array}$ \\
\hline $\begin{array}{l}\text { Solid-state } \\
\text { drug } \\
\text { substances }\end{array}$ & $\begin{array}{l}\text { Crystallization, } \\
\text { Nucleation, } \\
\text { Micronization, } \\
\text { Nanonization, } \\
\text { Lyophilization, } \\
\text { Amorphization, } \\
\text { Cocrystallization }\end{array}$ & $\begin{array}{l}\text { Melting point, } \\
\text { Particle morphology, } \\
\text { Particle size, } \\
\text { Particle density, } \\
\text { Crystal habit, } \\
\text { Surface area, } \\
\text { Porosity, } \\
\text { Particle shape, } \\
\text { Zeta potential, } \\
\text { Polymorphism, } \\
\text { Cocrystal }\end{array}$ & $\begin{array}{l}\text { Powderflowability, } \\
\text { Packability, } \\
\text { Compressibility, } \\
\text { Solubility, } \\
\text { Permeability } \\
\text { Stability } \\
\text { Reactivity, } \\
\text { Tabletability, } \\
\text { Dissolution rate, } \\
\text { Bioavailability }\end{array}$ \\
\hline
\end{tabular}

Scheme 1. Manufacturing processes affecting solid state characterization of drug substances. 
interaction, and API stability after exposure to elevated humidity and temperature over time should be conducted [24-27]. It is therefore necessary to use the comprehensive solid-state analytical approaches for ensuring and maintaining maximum quality control of an original API in pharmaceutical drug products $[6,28,29]$.

\section{The most commonly used solid-state analysis of APIs in drug products}

Newman and Byrn had reported that the solid APIs played an important role to impact the quality and consistency of the final solid oral dosage formulations [29]. Thus how to monitor and/or control the intact solid API continuously existed in drug product without any change from development to market and beyond is the most critical factor for successful drug development in the pharmaceutical industry [30-32]. In common, it is necessary to analyze each raw API, intermediate and final finished product at designated times to ensure the highest quality during pharmaceutical process development for supporting the regulatory filing activities [33,34]. Until now, many analytical techniques such as thermal, spectroscopic, and diffractometric methods have been often used to determine and confirm the original crystal form of API still existed in solid dosage forms after different pharmaceutical manufacturing processes [29-31,33-35]. Several unusual drug examples on the market had occurred undesired solid state conversion, resulting in poor bioavailability related problems or clinical failures [36,37].

Here, three most commonly used analytical techniques including thermal, spectroscopic, and diffractometric methods for solid-state analysis of APIs and drug products will be briefly described as follows.

\subsection{Thermal analysis}

Thermal analysis (TA) is one of the oldest analytical techniques for studying the thermal properties of different materials as a function of temperature or time $[38,39]$. In the field of pharmaceutical research,
TA has been often applied to investigate and characterize different pharmaceutical substances, such as physical stability (e.g., weight loss, loss of hydration/ solvation, degradation and/or decomposition), phase transitions (e.g., melting, sublimation, polymorph conversion) and other complex phenomena (e.g., chemical reaction, vitrification, relaxation, etc.) [40-44]. Four common TA techniques used in the pharmaceutical fields are thermogravimetric analysis (TGA), differential thermal analysis (DTA), differential scanning calorimetry (DSC), and thermomechanical analysis (TMA). The primary differences in these TA techniques and the properties measured of the materials are listed in Table 2. Hot-stage microscopy (HSM) is an another thermal method and can be used to visually examine many kinds of thermal transitions such as melting point, melting range, crystal nucleation, crystal growth, crystal transformations and others under a microscope, especially for the study of the visual color changes in the process of thermal transitions $[45,46]$.

\subsection{Vibrational spectroscopic technique}

The vibrational spectroscopy commonly includes mid-infrared (MIR), near-IR (NIR), and Raman spectroscopy. Fourier Transform Infrared (FTIR) spectroscopy is mainly used to measure MIR light absorption (wavelengths $2.5-25 \mu \mathrm{m}$ ). Both FTIR and Raman spectroscopies are complementary techniques, and offer rapid and non-invasive analysis to provide specific fingerprinting spectra for analysis of molecules in different scientific and industrial fields [47-50]. These techniques are indispensable analytical techniques in pharmaceutical analysis and can substantially identify and characterize the drug substances and excipients in drug discovery and formulation development, as well as in on-line pharmaceutical process manufacturing [51-54].

Both FTIR and Raman spectroscopies provide characteristic fundamental vibrations and are applied to the elucidation of molecular structure, whereas NIR spectroscopy is based on molecular overtones and combinations of vibrational modes to measure the absorption of electromagnetic radiation within wavelengths from 750 to $2500 \mathrm{~nm}$ [55-58].

Table 2. Conventional TA techniques and the representative properties measured for materials.

\begin{tabular}{lll}
\hline TA Technique & Abbreviation & Representative properties measured \\
\hline Thermogravimetric analysis & TGA & Decomposition, oxidation or loss of solvent or water \\
Differential thermal analysis & DTA & Melting points, glass transitions, phase changes \\
Differential scanning calorimetry & DSC & Melting points, heats of reaction, glass transition, heat capacity \\
Thermomechanical analysis & TMA & Expansion, contraction, penetration, softening, glass transition \\
Hot stage microscope & HSM & Thermal transition/crystal growth (Visual color change) \\
\hline
\end{tabular}


On the other hand, NIR spectroscopy as a powerful technique has recently been used for monitoring end-point of many pharmaceutical manufacturing processes, such as granulation, mixing or drying, since the NIR measurement not only requires no or little sample preparation but also is fast for online process control $[59,60]$.

In recent years, two new techniques of Terahertz Pulsed spectroscopy (TPS) and Terahertz Pulsed imaging (TPI) instruments are now commercially available for rapid and non-destructive analysis in pharmaceutical industry [61,62]. Both Terahertz techniques have been availably used for various pharmaceutical applications, such as (1) discrimination and quantification of polymorphism and crystallinity, (2) analysis of solid form transformation dynamics, (3) quantitative characterization of tablet film coatings: off-line and on-line, (4) tablet porosity measurement, (5) tablet coating and dissolution, (6) spectroscopic imaging and chemical mapping [61-66]. Fig. 1 shows different frequency ranges of the electromagnetic spectrum [67].

\subsection{Diffractometric technique}

X-ray diffraction (XRD) is a nondestructive technique used in solid state chemistry to characterize both organic and inorganic crystalline materials in various fields, as indicated in Fig. 2 [68,69]. XRD has a tremendous potential for solid state drug analysis in all stages of drug discovery and development, manufacturing and quality control of manufactured pharmaceutical products, in which XRD may

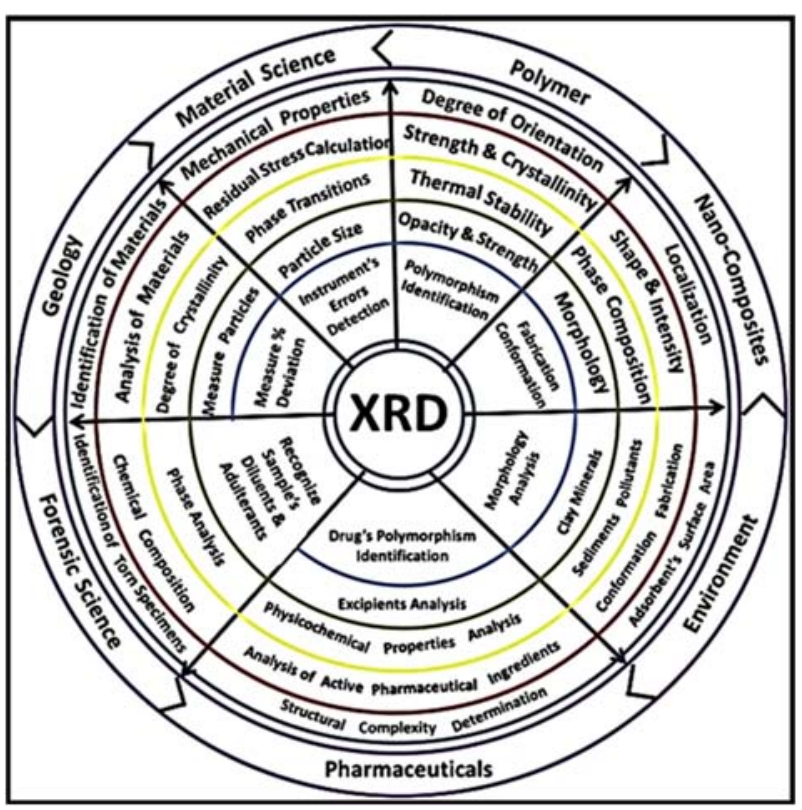

Fig. 2. Analytical applications of X-ray diffraction (XRD) in different fields [Reproduced from Ref. [68]].

provide more valuable pharmaceutical information on crystal structure, polymorphism, and degree of crystallinity and amorphous character of solid formulations, excipient compatibility, detection of impurities formed, stability studies, dosage uniformity, and manufacturing process control [70-72]. XRD is mainly based on Bragg's law, $2 d \sin \theta=n \lambda$, Where $d$ is the spacing between diffracting planes, $\theta$ is the incident angle, $n$ is an integer, and $\lambda$ is the beam wavelength. XRD patterns result from

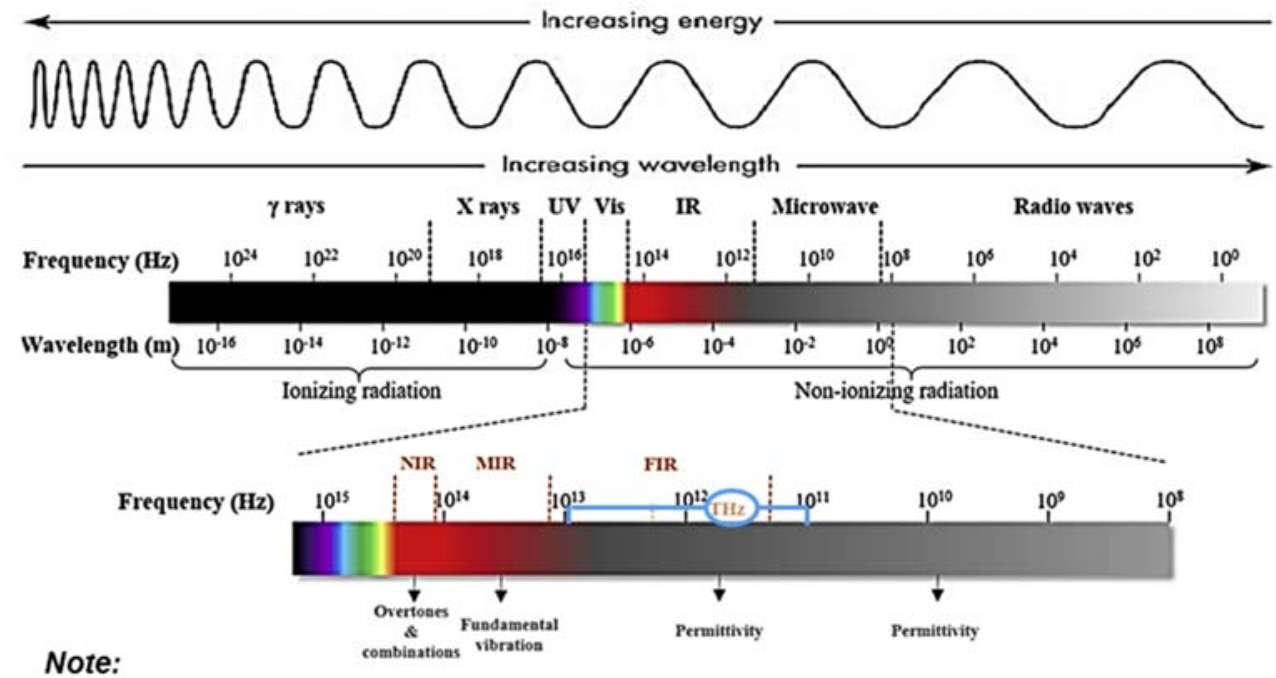

UV: UItraviolet; Vis: Visible; NIR: Near infrared; Mid IR: mid-infrared; FIR: Far infrared; THz: Terahertz

Fig. 1. Different frequency ranges of the electromagnetic spectrum [Modified, with permission from Ref. [67]]. 
electromagnetic waves impinging on a regular array of scatters, as shown in Fig. 1 [67]. The XRD pattern is the fingerprint of periodic atomic arrangements in a given material and commonly employed on thick or powdered materials due to its penetration depth of X-ray, resulting in the enhanced performance for detection of internal structural properties of the material [73].

The XRD analyzer consists of three key elements, $X$-ray source, a sample, and a detector, to pick up the diffracted X-rays [69]. Several scattering techniques of $X$-ray crystallography have been reported: single-crystal diffraction, powder diffraction, fiber diffraction, small-angle and wide-angle $X$-ray scattering [74]. Two major techniques, powder $X$-ray diffraction (PXRD) and single-crystal X-ray diffraction (SCXRD), are the most common approaches used in pharmaceutical investigation [75,76].

PXRD can characterize the structural properties of powders or microcrystalline solid materials, whereas SCXRD may determine three dimensional arrangements of atoms in a crystalline chemical compound. Particularly, PXRD has always applied to the pharmaceutical industry via solid-state analysis of a drug substance or product in various stages of drug development and manufacturing process as follows: (1) API characterization and excipient identification (phase analysis and polymorph screening, crystallinity determination, control of ingredients), (2) determination of physical and chemical stability (compatibility studies, stability studies), (3) monitoring for solid form conversion upon manufacturing (process control, manufacturing and production), (4) verification of the solid form of the API in the drug product (batch/ dosage uniformity, impurities product) [77-80].

\section{Hyphenated analytical techniques applied to pharmaceutical analysis}

In recent years, hyphenated analytical techniques have received considerable attention as unique analytical tools for solving various complex problems in pharmaceutical analysis [81-85]. The merits of hyphenated analytical techniques have remarkably broadened their applications in the analysis of biomaterials, natural products, cosmetics, pharmaceuticals and biomedical products. The hyphenated technique simply connects two or more analytical instruments together to enhance material characterization with an appropriate interface [86]. The term "hyphenated techniques" may range from the combination of separation-separation, separationidentification and identification-identification techniques [87]. The hyphenated analytical method has been able to provide faster and more reliable results than that a traditional single instrumental method.

The technique developed by coupling a separation technique and an on-line spectroscopic detection (identification) technology is the most used hyphenated technique, thus Patel et al. had discussed the use of five available hyphenated techniques, e.g., gas chromatography-mass spectroscopy (GC-MS), liquid chromatography-Fourier transform infrared (LC-FTIR), LC-MS, LC-nuclear magnetic resonance spectroscopy (LC-NMR), capillary electrophoresis-MS (CE-MS), for preisolation analyses of crude extracts or fraction from various natural sources, isolation and on-line detection of natural products, chemotaxonomic studies, chemical fingerprinting, quality control of herbal products, and etc. [81]. The GC, LC and CE were as the separation tool in the hyphenated techniques, whereas FTIR, MS and NMR were utilized as identification tool. The combination of both separation tools with identification techniques has been demonstrated for years to qualify and quantify the unknown compounds in complex natural product extracts or fractions [81].

Ermer and Vogel had successfully introduced the applications of hyphenated LC-MS techniques in pharmaceutical analysis, in which LC-MS might systematically be applied to monitor and identify the impurity profiles during pharmaceutical development and scaling up for supporting the safety evaluation of batches used in clinical studies [88]. In addition, Pan et al. had reviewed and discussed the current analytical strategies for chemical and structural identification of pharmaceutical impurities [89]. Because the pharmaceutical impurities had pharmacological or toxicological effect, the presence of these impurities and their levels in drug products often had critical impacts on the quality of drug products and the safety of patients. Thus understanding drug impurities or drug degradation products in the formulated products must be conducted. The LC-MS had been widely used in the pharmaceutical industries due to its excellent sensitivity for the detection of trace level of impurities and degradation products observed in formulated dosage forms. Sometimes, other hyphenated analytical techniques such as LC-NMR, GC-MS, and size-exclusion chromatography (SEC)/chemiluminescent nitrogen detectors (CLND) were also used to identify and confirm the final structures of impurities as required during dosage form development.

In addition, the identification-identification modes of hyphenated techniques had also been applied to polymeric and pharmaceutical industries 
by coupling TA techniques with spectroscopic technique [90-96]. TA techniques were commonly well-established techniques used for characterization of polymers and pharmaceuticals. A single TA technique simply measured the change of a specific property of materials as a function of temperature, whereas the hyphenated techniques coupled with different analytical techniques and equipped with a proper interface could enable user to determine more information from complex matrices $[44,83,87,96]$. Therefore, the application of the hyphenated analytical techniques in pharmaceutical analysis has offered great advances [84-88,97-101].

\section{Simultaneous DSC-FTIR microspectroscopy}

It had been reported that TA techniques could only measure the physical properties of materials; it was often incomplete and/or limited in its ability to address chemical composition and structure [102]. In order to overcome the limitation of TA techniques, coupling TA instruments with chromatographic or spectral instruments to increase the information collected during the experiment is one of the most important challenges [83-87,103]. Analysis of complex samples has been greatly assisted by the coupling of FTIR analysis to the TA experiment [91,94]. The combination of DSC and FTIR spectroscopy gives important spectroscopic and thermodynamic information for a solid or liquid sample upon heat treatments [90-94]. The DSCFTIR technique is being more widely recognized as a powerful tool for understanding the thermaldependent structural behaviour. The most promising research areas are probably polymers and the polymorphism of pharmaceuticals $[90,91,94]$.

\subsection{Introduction of DSC}

DSC is a fundamental tool and also the most commonly used TA tool for investigating the temperature-driven phase changes of different materials. DSC can measure the transition such as the melting, crystallization, and glass transition of materials from polymers to foods and to pharmaceuticals [22,38-43]. DSC not only measures directly the endothermic or exothermic behavior of a material as a function of temperature, but also provides qualitative and quantitative information of thermodynamic parameters such as glass transition temperature $(T g)$, melting temperature $(T m)$, crystallization temperature $(T c)$, and thermal properties such as the enthalpy $(H)$, heat capacity $(C p)$ $[38-43,104]$. However, Menard et al. pointed out that DSC lacked structural or chemical information from its DSC thermogram [102,103], in which DSC only provided the thermal properties of solid materials. The structural or chemical information of solid samples must be obtained from other analytical methods.

\subsection{DSC coupling with FTIR spectroscopy}

Although DSC is a well-known analytical tool to measure the temperature-dependent phase changes and various kinetic parameters, it is also used to combine with a few analytical instruments only so far. DSC has only been found in conjunction with FTIR spectroscopy (DSC-FTIR), mass spectrometry (DSC-MS) or X-ray diffraction [90,91,105-108]. Two simultaneous DSC-FTIR combined systems had first been studied in 1986 by two groups of researchers to examine the structural changes of polypropylene during melting or to monitor the morphological transitions on the hydrogen bonding of polyurethanes, respectively $[90,105]$.

The DSC coupling with FTIR spectroscopy deals with the thermal and spectral information to be derived simultaneously from a single sample. This simultaneous DSC-FTIR technique gives thermodynamic and spectroscopic information about a solid or liquid sample upon thermal treatment $[44,90,91,105]$, in which DSC measured the endothermic and/or exothermic responses of the samples, while the FTIR analysis detected thermal changes in chemical and physical compositions. The possible merits of this DSC-FTIR combined system may be proposed as follows: (1) the same sample for both determinations; (2) the identical thermal and chemical environments; (3) real time response to both thermal and chemical events, and (4) a short analysis time [109]. Therefore, this DSC-FTIR coupled technique can be used easily and effectively to study the thermal and spectral properties of pharmaceuticals in real time.

\subsection{DSC-FTIR instrument configuration}

As described above, the hyphenation of DSC with FTIR microspectroscopy had first been used in 1986 [90,105]. This DSC-FTIR combined technique can simultaneously provide the thermodynamic and spectroscopic information of the sample under thermal treatment at the same time. In this approach, the whole instrument of DSC-FTIR microspectroscopic system used in my laboratory is shown in Fig. 3. This DSC-FTIR combined system involves the use of a miniature DSC cell positioned under the objective of an IR microscope in conjunction with FTIR spectroscopy. A computer 


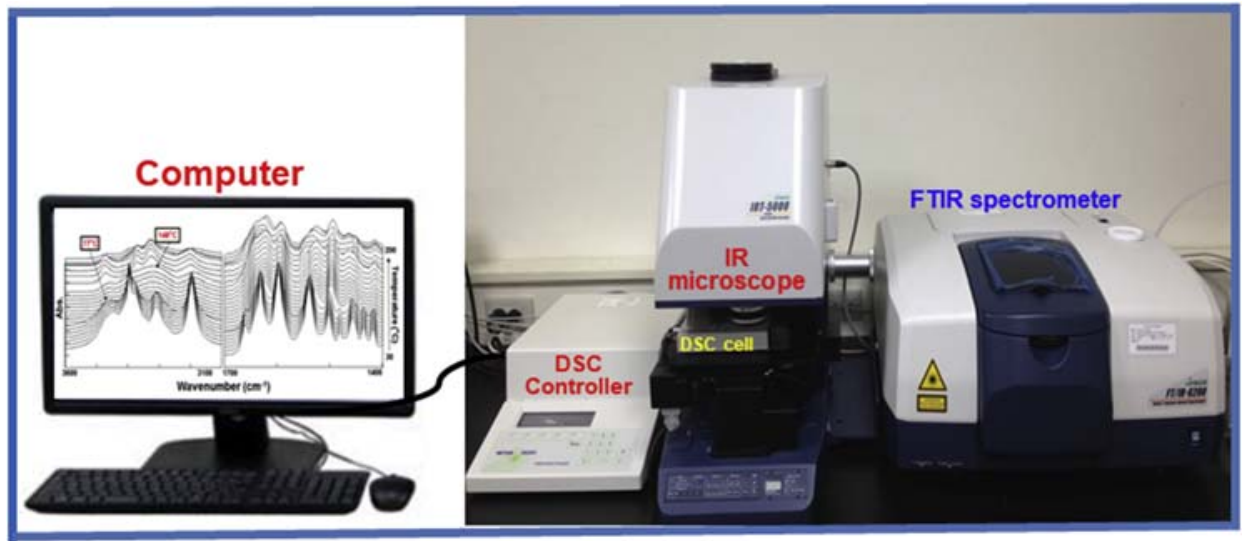

Fig. 3. The instrumental configuration of a DSC-FTIR microspectroscopic apparatus [Modified, with permission from Ref. [44]].

directly monitors DSC and FTIR analyses, and the overall operation permits the simultaneous collection of both data sets. In this combined system, DSC can measure the thermal responses of the samples, whereas FTIR analysis determines the changes in their structure simultaneously.

This FTIR microspectroscopy is commonly equipped with mercury cadmium telluride (MCT) as a detector in the narrow and mid-band wavelength range between 4000 and $650 \mathrm{~cm}^{-1}$. The FTIR spectra are generated by co-addition of 256 interferograms collected at $4 \mathrm{~cm}^{-1}$ resolution. The MCT detector used with an IR microscope has a much greater sensitivity, which is suited to the measurement of micrometer sized samples common for microscopic measurements. However, the MCT detector has some disadvantages such as the requirement for liquid nitrogen cooling for measurements, a reduced absorbance linearity and a reduced wavenumber range for measurements. Recently, a new deuterated L-alanine triglycine sulphate (DLATGS) detector has been developed for IR microscopy with wide wavenumber range between 4000 and $450 \mathrm{~cm}^{-1}$ at ambient temperatures to meet various measurement purposes, especially focusing on an increased sensitivity [110].

In my laboratory, the hot stage microscopy is used as a DSC cell, which is a precise thermal measurement cell for simultaneous visual observation and heat flow measurements. In the instrument configuration, the IR beam passes through a hole in the DSC cell via the IR microscope to the MCT detector. The samples are generally mounted on an optically transparent medium of potassium bromide $(\mathrm{KBr})$ pellet and then placed it in a hole in the DSC cell, which can be used as the transmission or reflectance mode. A careful alignment procedure is required prior to the operation. This simple and time-saving system relies on a one-step continuous process and provides the correlation between thermal response and spectral information regarding structural changes occurring in the sample. Moreover, this combined system may also be acted as an accelerated stability testing apparatus to predict the thermal stability of samples. This unique DSC-FTIR combined system has been extensively applied to quickly investigate the thermal-induced structural changes and stability of foods, polymers, pharmaceuticals, excipients, and cocrystal formation $[44,99,111]$.

\subsection{DSC-FTIR microspectroscopy for rapid solid- state analysis of drugs and pharmaceutical polymers or excipients}

The solid-state chemistry of drugs has received major attention from the pharmaceutical industry and has become an increasingly important benchmark in drug development because solid-dosage forms are the most commonly used preparations $[98,99]$. A better understanding of solid state properties of an API is essential for pharmaceutical drug development and should be the first priority in the design of oral solid dosage drugs. This DSC-FTIR microspectroscopy can simultaneously establish the correlation between the thermal response and the IR spectral information of structural changes of the drug sample. This technique not only can simulate the accelerated stability test, but also may simultaneously detect the decomposed products in real time. The current review attempts to provide a succinct update of DSC-FTIR microspectroscopy used on the investigation of the solid state analysis of different drugs and polymers or excipients (Table $3)$, the details are as follows. 
Table 3. A DSC-FTIR microspectroscopy used for investigation of the solid state analysis of different drugs and polymers or excipients.

\begin{tabular}{|c|c|c|c|c|}
\hline $\begin{array}{l}\text { Intramolecular } \\
\text { condensation }\end{array}$ & $\begin{array}{l}\text { Intramolecular cyclization } \\
\text { (DKP formation) }\end{array}$ & $\begin{array}{l}\text { Polymorphic } \\
\text { transformation }\end{array}$ & $\begin{array}{l}\text { Drug-polymer (excipient) } \\
\text { interaction }\end{array}$ & $\begin{array}{l}\text { Cocrystal screening } \\
\text { and formation }\end{array}$ \\
\hline $\begin{array}{l}\text { Silicone elastomer } \\
\quad \text { (Ref. [112]) }\end{array}$ & $\begin{array}{l}\text { Lisinopril dihydrate } \\
\text { (Ref. [130]) }\end{array}$ & $\begin{array}{l}\text { Acetaminophen } \\
\text { (Ref. }[147,148])\end{array}$ & $\begin{array}{l}\text { Eudragit L-theophylline } \\
\text { (Ref. [163]) }\end{array}$ & $\begin{array}{l}\text { Carbamazepine-glutaric acid } \\
\text { (Ref. [188]) }\end{array}$ \\
\hline $\begin{array}{l}\text { Eudragit } L \\
\quad \text { (Ref. [113-115]) }\end{array}$ & $\begin{array}{l}\text { Enalapril Maleate } \\
\text { (Ref. }[131,132])\end{array}$ & $\begin{array}{l}\text { Famotidine } \\
\text { (Ref. [149]) }\end{array}$ & $\begin{array}{l}\text { Eudragit E-enalapril maleate } \\
\text { (Ref. [164]) }\end{array}$ & $\begin{array}{l}\text { Indomethacin-saccharin } \\
\text { (Ref. [188-184,194]) }\end{array}$ \\
\hline $\begin{array}{l}\text { Eudragit E } \\
\quad \text { (Ref. [116]) }\end{array}$ & $\begin{array}{l}\text { Aspartame hemihydrate } \\
\text { (Ref. }[133,134] \text { ) }\end{array}$ & $\begin{array}{l}\text { Metoclopramide } \\
\text { HCl monohydrate } \\
\text { (Ref. }[150,151])\end{array}$ & $\begin{array}{l}\text { Asparagine-glucose } \\
\text { (Ref. [165]) }\end{array}$ & $\begin{array}{l}\text { Theophylline-citric acid } \\
\text { (Ref. [190,191]) }\end{array}$ \\
\hline $\begin{array}{l}\text { Eudragit S } \\
\qquad \text { (Ref. [117]) }\end{array}$ & $\begin{array}{l}\text { Gabapentin } \\
\text { (Ref. [138]) }\end{array}$ & $\begin{array}{l}\text { Indomethacin } \\
\text { (Ref. }[152,153])\end{array}$ & $\begin{array}{l}\text { Metoclopramide } \mathrm{HCl} \\
\text { monohydrate- } \mathrm{KBr} \\
\text { (Ref. [166]) }\end{array}$ & $\begin{array}{l}\text { Metaxalone-succinic acid } \\
\text { (Ref. [192]) }\end{array}$ \\
\hline $\begin{array}{l}\text { Eudragit L30D } \\
\quad \text { (Ref. [117]) }\end{array}$ & & $\begin{array}{l}\text { Trehalose dihydrate } \\
\text { (Ref. [154]) }\end{array}$ & $\begin{array}{l}\text { Human serum albumin } \\
\text { (HSA)-ribose } \\
\text { (Ref. [167]) }\end{array}$ & $\begin{array}{l}\text { Indomethacin-nicotinamide } \\
\text { (Ref. }[193,195])\end{array}$ \\
\hline $\begin{array}{l}\text { Carbopol } \\
\quad \text { (Ref. [117]) }\end{array}$ & & $\begin{array}{l}\text { Raffinose pentahydrate } \\
\text { (Ref. [155]) }\end{array}$ & & $\begin{array}{l}\text { Piroxicam-saccharin } \\
\text { (Ref. [196]) }\end{array}$ \\
\hline $\begin{array}{l}\text { PVA copolymer } \\
\text { (POVACOAT) } \\
\text { (Ref. [119]) }\end{array}$ & & $\begin{array}{l}\text { Captopril } \\
\text { (Ref. [160]) }\end{array}$ & & \\
\hline
\end{tabular}

\subsubsection{Solid-state intramolecular condensation of pharmaceutical polymers}

Lin et al. used a DSC-FTIR microspectroscopy to examine the curing kinetics of silicone elastomer via intramolecular condensation [112]. This DSC-FTIR microspectroscopy was a very rapid and convenient apparatus for determination of the curing kinetics of medical grade silicone elastomer (MDX-4-4210), in which the change in IR peak intensity of $\mathrm{Si}-\mathrm{H}$ at $2162 \mathrm{~cm}^{-1}$ for the curing agent might be acted as a reaction marker. The IR peak intensity of the $\mathrm{Si}-\mathrm{H}$ band was decreased with the increase in temperature during curing process, which might be attributed to the curing reaction occurred between $\mathrm{Si}-\mathrm{H}$ (curing agent) and $\mathrm{CH}_{2}=\mathrm{CH}_{2}$ (elastomer), leading to reduction of the amount of $\mathrm{Si}-\mathrm{H}$ groups in the reaction mixture. In addition, the curing temperature and normal hydrocarbon alcohols added significantly influenced the curing process of silicone elastomer, in which the curing reaction might be described by first-order kinetics.

Lin and co-workers had used DSC-FTIR microspectroscopy to extensively examine an intramolecular interaction occurred in a series of methacrylic acid copolymers such as Eudragit L, S, E, RL, RS, L30D, E30D, PVA copolymer, and carbopol by nonisothermal or isothermal method with transmission or reflectance model [113-119]. A 6membered cyclic anhydride formation was respectively produced by heating each Eudragit L, S, E or L30D, PVA copolymer or carbopol via inter- or intramolecular ester condensation. Eudragit $\mathrm{E}$ as an example, the anhydride-related IR peak intensities at 1801 and $1763 \mathrm{~cm}^{-1}$ (asymmetric and symmetric stretching vibration mode of the $\mathrm{C}=\mathrm{O}$ group in an anhydride structure) as well as $1007 \mathrm{~cm}^{-1}$ (asymmetric stretching mode of $\mathrm{C}-\mathrm{O}-\mathrm{C}$ for a cyclic anhydride) appeared from $180{ }^{\circ} \mathrm{C}$ and increased with the heating temperature, suggesting that the anhydride formation via ester condensation started above $180{ }^{\circ} \mathrm{C}$ (Fig. 4) [116]. Moreover, the higher peak intensity ratio of $1763 \mathrm{~cm}^{-1} / 1801 \mathrm{~cm}^{-1}$ also exhibited the predominant role of intramolecular ester condensation in anhydride formation for Eudragit E film. However, Eudragit RL, RS, or E 30D polymer revealed a higher thermal-stable behavior without ester condensation [118]. In addition, the $T g$ of different polymers was also easily and rapidly measured by DSC-FTIR analysis in a short time, as compared other techniques [120].

\subsubsection{Solid-state intramolecular cyclization of drugs and sweetener}

A better understanding of drug stability in various dosage forms and their regulatory requirements are essential for pharmaceutical researchers. The intramolecular aminolysis occurred in protein drugs is also an important stability problem for formulating these drugs with or without different excipients [121-123]. The intramolecular cyclization of amino and carboxylic acid, ester, or amide, groups at the $\mathrm{N}$-terminus of a peptide or protein, to form diketopiperazine (DKP) is a key degradation pathway during peptide synthesis or long-term storage [121-125]. The detailed mechanism of DKP formation from dipeptide amides involves the nucleophilic attack of the $\mathrm{N}$-terminal nitrogen at the amide carbonyl carbon-atom, between the second and 

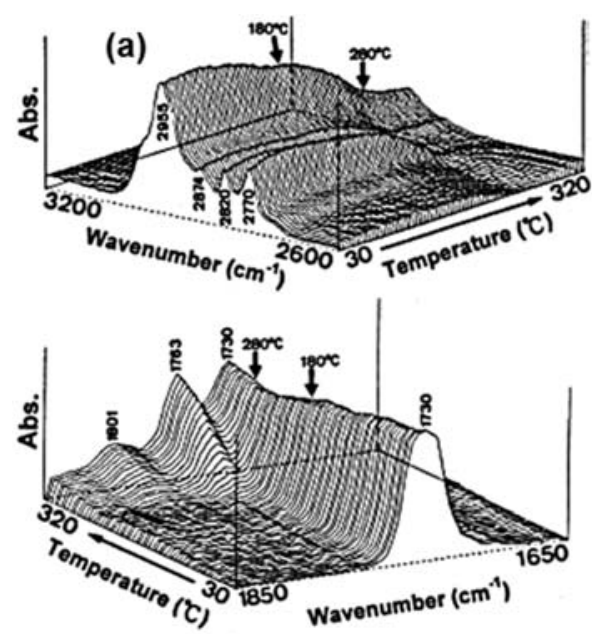

(b)
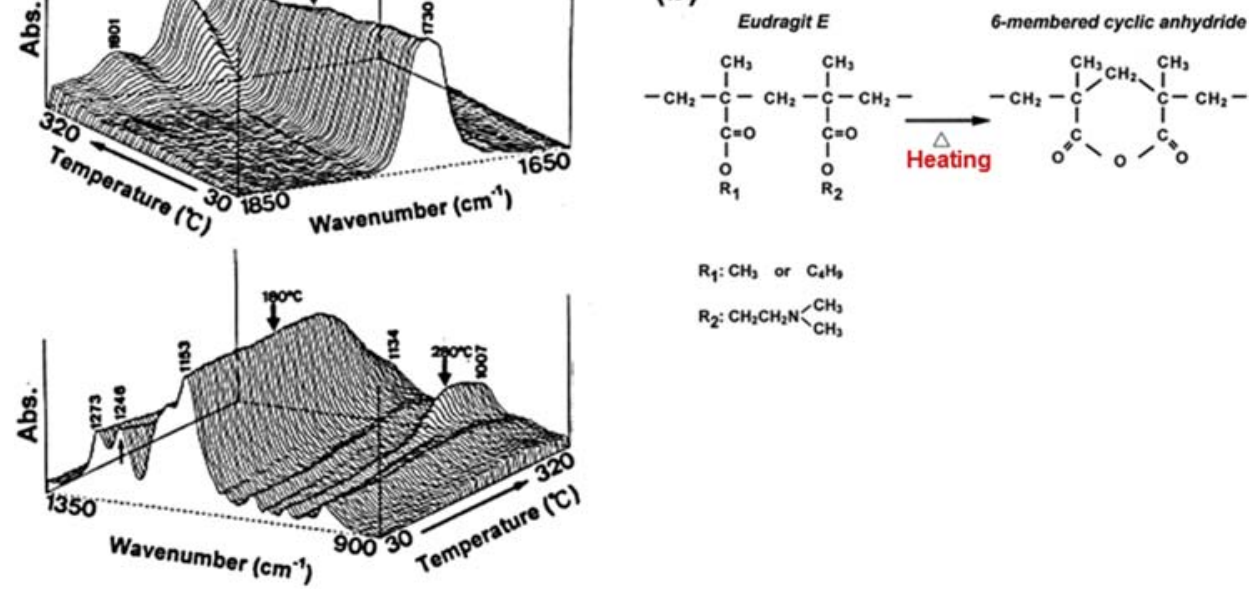

$\mathrm{R}_{\mathbf{1}}: \mathrm{CH}_{3}$ or $\mathrm{C}_{4} \mathrm{H}_{\mathbf{2}}$

$\mathrm{R}_{2}: \mathrm{CH}_{2} \mathrm{CH}_{2} \mathrm{~N}_{\mathrm{CH}}^{-} \underset{\mathrm{CH}}{\mathrm{CH}}$

Fig. 4. Three-dimensional plots of reflectance FTIR spectra of Eudragit E film with respect to the temperature (a) and the scheme for six-membered cyclic anhydride formation via heating process (b) [Modified, with permission from Ref. [116]].

third amino acids. Until now, several analytical methods have been used to investigate the stability and DKP formation of these dipeptide drugs in solid and liquid states [99,126-129].

A simultaneous DSC-FTIR technique for real-time induction and detection of DKP formation from the pharmaceutical dipeptides including lisinopril dihydrate, enalapril maleate and aspartame hemihydrate had been examined by Lin and colleagues [99,130-134]. Lisinopril dihydrate as an example, the three-dimensional plots of FTIR spectra of lisinopril dihydrate as a function of temperature between $3700-2500$ and $1800-1200 \mathrm{~cm}^{-1}$ of wavenumbers is displayed in Fig. 5 [130]. A new peak at $1670 \mathrm{~cm}^{-1}$ assigned to the carbonyl band of DKP formation was clearly evidenced. The water of reaction byproduct was liberated at a temperature $>100{ }^{\circ} \mathrm{C}$ and appeared on the IR spectra near 3200$3400 \mathrm{~cm}^{-1}$. Moreover, the peak at $1574 \mathrm{~cm}^{-1}$ assigned to carboxylate was shifted to $1552 \mathrm{~cm}^{-1}$ due to the DKP formation. The peak intensity at $1670 \mathrm{~cm}^{-1}$ related to the DKP formation was changed slightly from $147^{\circ} \mathrm{C}$ but significantly above $157^{\circ} \mathrm{C}$. Because both DSC and TGA methods are hard to show up lisinopril DKP formation, the DSCFTIR microscopic system can be considered to be a useful technique to quickly and directly detect the solid-state stability of drug [130]. The pathway of two consecutive dehydration processes and intramolecular cyclization of DKP formation in solidstate lisinopril dihydrate had been examined by this one-step DSC-FTIR microscopy, as shown in Fig. 6 [130]. The solid-state lisinopril dihydrate exhibited two step dehydration processes: the first process was from dihydrate to monohydrate at $76^{\circ} \mathrm{C}$ and then the second process was from monohydrate to anhydrate at $99-101{ }^{\circ} \mathrm{C}$. The DKP formation was continuously occurred after $147{ }^{\circ} \mathrm{C}$ via intramolecular cyclization in solid-state anhydrous lisinopril. The DKP formation might be as an impurity existed in pharmaceutical dosage forms. Similar results are also observed for enalapril maleate and aspartame hemihydrate [131-134].

In addition, Widjaja et al. had successfully used the multivariate data analysis approach based on entropy minimization and spectral dissimilarity to investigate the solid-state kinetics of intramolecular cyclization of enalapril maleate via thermal FTIR microscopy [135]. The infrared spectra of enalapril maleate and DKP were reconstructed. Their kinetic analysis revealed that the process of degradation required about $176.4-193.9 \mathrm{~kJ} / \mathrm{mol}$ of activation energy based on fitting the fraction decomposed of enalapril maleate to seven nucleation models. 


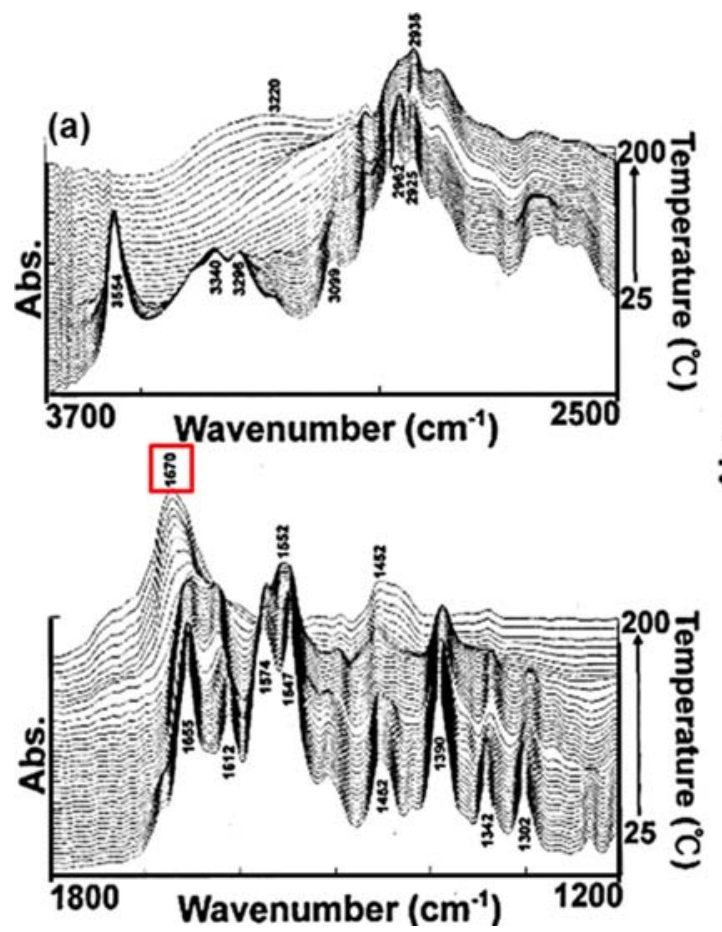

\section{(b)}

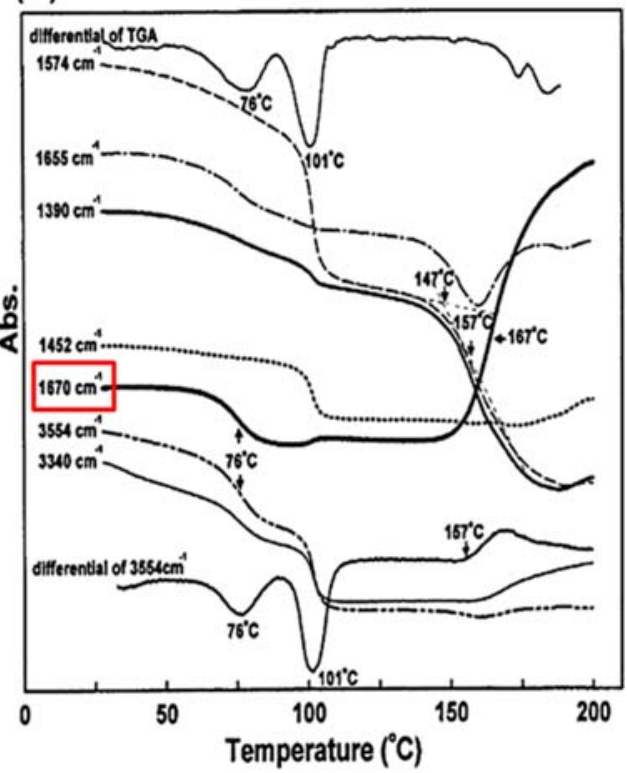

Fig. 5. Three-dimensional plots of FTIR spectra of solid-state lisinopril dihydrate a function of temperature (a) and temperature-dependent changes in peak intensity of the selected IR banks of lisinopril dihydrate (b) [Modified, with permission from Ref. [130]].

Moreover, Tan and Widjaja further interpreted the pathway of dehydration and intramolecular cyclization of lisinopril dihydrate in the solid state via isothermal FTIR microscopy by using advanced multivariate chemometric approach [136,137]. The estimated activation energy of the intramolecular cyclization reaction of lisinopril was about $327 \mathrm{~kJ} /$ mol.

\section{Lisinopril dihydrate}<smiles>NCCCC[C@H](N[C@@H](O)CCc1ccccc1)C(=O)N1CCC[C@H]1C(=O)O</smiles><smiles>NCCCCC1C(=O)N2CCCC2C(=O)N1C(CCc1ccccc1)C(=O)O</smiles>

Lisinopril diketopiperazine

\section{Lisinopril monohydrate}<smiles>NCCCC[C@H](O)N[C@@H](Cc1ccccc1)C(=O)N1CCC[C@H]1C(=O)O</smiles>

$99-101^{\circ} \mathrm{C}$ Dehydration

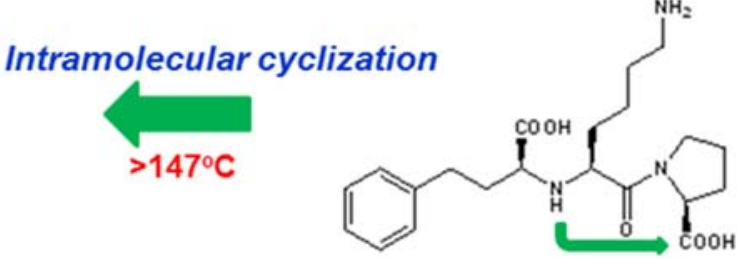

Lisinopril anhydrate

Fig. 6. The pathway of two consecutive dehydration processes and intramolecular cyclization pathway of DKP formation in solid-state lisinopril dihydrate [Modified, with permission from Ref. [130]]. 
The detailed intramolecular lactamization process of gabapentin (GBP) to form gabapentin-lactam (GBP-L) was also studied by Hsu and Lin via onestep DSC-FTIR microspectroscopy [138]. This DSCFTIR microspectroscopy clearly evidenced that the IR spectral peak at $3350 \mathrm{~cm}^{-1}$ for water liberated was found and at $1701 \mathrm{~cm}^{-1}$ for lactam structure was formed due to the lactam formation of GBP. In addition, the intramolecular lactamization GBP was easily determined in the GBP sample prepared by embedding it into $2 \mathrm{KBr}$ method rather than $1 \mathrm{KBr}$ method.

\subsubsection{Solid-state polymorphic transformation of drugs and excipients}

The polymorphic forms of a drug have a profound impact on the physicochemical properties like dissolution and solubility, chemical and physical stability, flowability and hygroscopicity, resulting in a significant influence on the stability and bioavailability of drug products [37,139-141]. In recent years, the change of the polymorphic form of APIs has frequently caused problems in bioavailability and clinical failures once it is on the market [36,37,140-143]. Recently, many some advanced analytical techniques have been applied to characterize the polymorphs and polymorphic transformation [144-146]. In my researches, this one-step powerful DSC-FTIR combined system has been designed to quickly investigate the thermal-induced polymorphic interconversion processes of drugs involving acetaminophen, famotidine, gabapentin, indomethacin, metoclopramide $\mathrm{HCl}$ monohydrate, trehalose dihydrate, raffinose pentahydrate in the solid state, too [147-155].

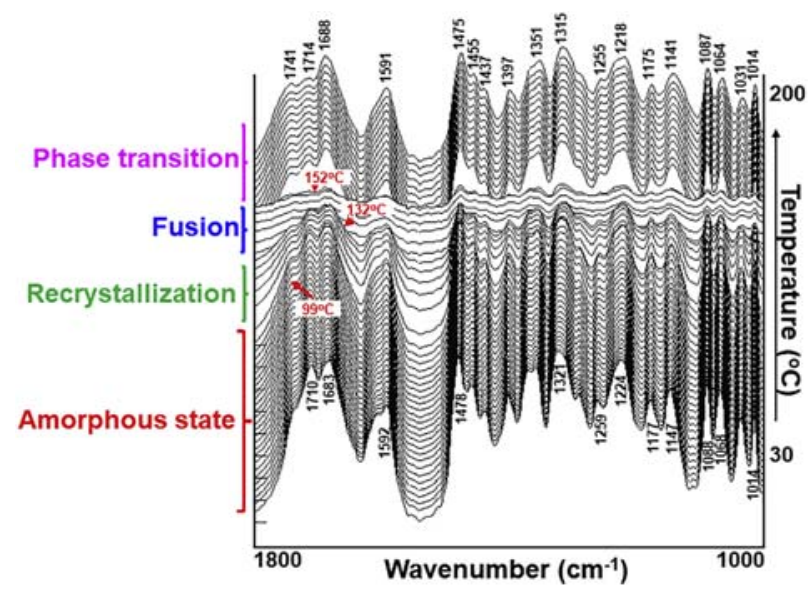

Fig. 7. Continuous phase transitional changes in the three-dimensional FTIR plot of amorphous indomethacin (IMC) in the solid state [Modified, with permission from Ref. [153]].
Indomethacin (IMC) as an example, IMC has several polymorphic forms and one amorphous form [156]. Fig. 7 displays the continuous phase transitional changes in the three-dimensional FTIR results of amorphous IMC measured by the simultaneous DSC-FTIR method [153]. It is evident that the thermal-related changes in IR peak intensity for several specific spectra were clearly observed. These spectral changes significantly differed from that of the spectral changes for $\gamma$-IMC (did not change). Four undulating regions of the IR peak intensities were obviously observed in the three-dimensional FTIR contour profile. There were no substantial changes in the contour profile of sharp IR peaks before $99{ }^{\circ} \mathrm{C}$ (amorphous state). Once the temperature was $>99{ }^{\circ} \mathrm{C}$, all the IR peak intensities were slightly increased as the temperature was increased from $99{ }^{\circ} \mathrm{C}$ to $132{ }^{\circ} \mathrm{C}$ due to the occurrence of recrystallization. Beyond $132{ }^{\circ} \mathrm{C}$, all the IR spectral peaks became broader and less intense. However, the sharp IR peak intensities reappeared at temperatures $>152{ }^{\circ} \mathrm{C}$. The less intense of IR peaks within $132^{\circ} \mathrm{C}-152{ }^{\circ} \mathrm{C}$ might be due to the fusion of the recrystallized IMC. The sharp IR peak intensities above $152{ }^{\circ} \mathrm{C}$ should be corresponded to the phase transformation from the molten IMC to $\alpha$-IMC and $\gamma$-IMC. The reappearance of the sharp IR peaks at 1741 and $1714 \mathrm{~cm}^{-1}$ was explained by this phenomenon. The thermal-dependent successive conformational changes of amorphous IMC sample were directly and clearly evidenced by DSC-FTIR microspectroscopy.

Another continuous process of solid-state dehydration, amorphization and recrystallization of metoclopramide hydrochloride monohydrate (MCP $\mathrm{HCl} \mathrm{H}_{2} \mathrm{O}$ ) was also determined by this simultaneous DSC-FTIR microspectroscopic technique [150,151]. During the thermal treatment, three undulating regions of FTIR spectral peak intensities in the contour profile displayed a marked change. As shown in Fig. 8, there was a less significant change in the contour profile before $77^{\circ} \mathrm{C}$. Once the heating temperature was $>77^{\circ} \mathrm{C}$, all the IR peaks became broadened and weaker in intensities. However, the sharp IR peak intensities again appeared at temperatures $>148{ }^{\circ} \mathrm{C}$. Both weak and less intense IR peaks from 77 to $148{ }^{\circ} \mathrm{C}$ might be due to the amorphous formation after quick dehydration of $\mathrm{MCP}$ $\mathrm{HCl} \mathrm{H}_{2} \mathrm{O}$, which resulted in a random structure in the crystal lattice. The starting temperature of $77^{\circ} \mathrm{C}$ was close to that of the thermal change at $78{ }^{\circ} \mathrm{C}$ in the TGA and DSC curves. Given that the amorphous form of $\mathrm{MCP} \mathrm{HCl}$ is unstable during heating, it quickly recrystallized near $148{ }^{\circ} \mathrm{C}$ and sharpened the IR band from broad shape. Obviously, the 


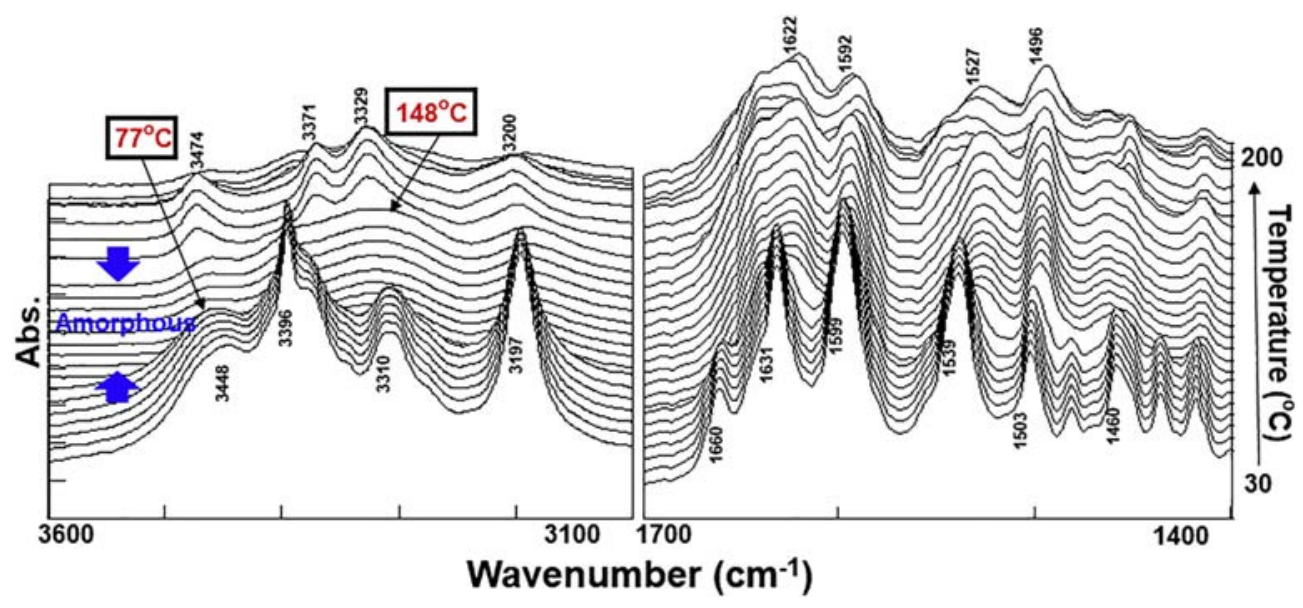

Fig. 8. Continuous phase transitional changes in the three-dimensional FTIR plot of solid-state metoclopramide hydrochloride monohydrate (MCP $\mathrm{HCl} \mathrm{H}_{2} \mathrm{O}$ ) [Modified, with permission from Ref. [150]].

thermal-dependent 3D plot of the FTIR spectra clearly indicated both amorphization and recrystallization processes after dehydration of $\mathrm{MCP} \mathrm{HCl}$ $\mathrm{H}_{2} \mathrm{O}$ in a one-step determination. This suggests that one-step simultaneous DSC-FTIR microspectroscopy is useful for studying changes in the progressive processes of dehydration, amorphization and recrystallization of solid-state $\mathrm{MCP} \mathrm{HCl}$ $\mathrm{H}_{2} \mathrm{O}$.

Lin and Cheng also used a thermal micro-Raman spectroscopy to determine the phase transformation of solid-state MCP $\mathrm{HCl} \mathrm{H} \mathrm{H}_{2} \mathrm{O}$ [157]. Three steps of phase transformation were dehydration, recrystallization, and new crystal formation, which were markedly correlated with the endothermic and exothermic results of DSC study and the observations of HSM. The results generally indicated that MCP $\mathrm{HCl} \mathrm{H}_{2} \mathrm{O}$ crystals were first dehydrated to form an anhydrous sample, then recrystallized and transformed to a new crystal form of $\mathrm{MCP} \mathrm{HCl}$ anhydrate. Similar studies of famotidine under different compression pressures or milling processes were also examined by thermal micro-Raman spectroscopic mapping study [158,159].

Wang et al. also investigated the conformational isomerization of captopril in the solid state by DSCFTIR microspectroscopy [160]. The results demonstrated that the intact captopril was existed as trans isomer form in the solid state by intramolecular hydrogen bonding, but after heating the captopril sample to $>102{ }^{\circ} \mathrm{C}$, several new bands at 1720,1645 , and $1610 \mathrm{~cm}^{-1}$ were observed with the increase of temperature, indicating the coexistence of a cis isomer. However, the cis isomer could transform gradually to the trans isomer after cooling. The trans isomer was more stable than the cis isomer, but the cis isomer was favored at the higher temperature.

\subsubsection{Solid-state drug-polymer (excipient) interaction}

The drug-excipient compatibility study is an important topic and process in the pre-formulation stage of drug development [26,27,161,162], in which the potential interaction between drug and polymer or excipient has impacts on the physical, chemical, bioavailability and stability of the drug dosage forms. In mylaboratory, the drug-polymer interaction of theophylline and Eudragit L or enalapril maleate and Eudragit $\mathrm{E}$ in the solid state was also confirmed by using one-step DSC-FTIR microspectroscopy $[163,164]$. Due to the interaction between theophylline and Eudragit L was occurred, leading to having a higher glass transition temperature of the cast film than that of their physical mixture or Eudragit L-100 alone. An interaction between theophylline and Eudragit L-100 was also found in the physical mixture during DSC heating. Moreover, the formation of an acid anhydride by a crosslinking process also took place in Eudragit L-100 polymer at elevated temperature [163].

On the other hand, the mechanism of solid-state interaction between enalapril maleate and Eudragit $E$ was also determined by this unique technique. When the weight ratio of both components was 1:1, Eudragit E might interact with the carboxyl group of maleic acid to exacerbate the degradation of enalapril maleate. However, the excess amount of Eudragit E might somewhat reduce the degradation of enalapril, due to the interaction that occurred between Eudragit E and carboxyl group of enalapril [164]. 
Hwang et al. also used this DSC-FTIR technique to investigate the stepwise reaction pathway of the solid-state Maillard reaction between glucose and asparagine [165]. It clearly found that the successive reaction products such as Schiff base intermediate, Amadori product and decarboxylated Amadori product in the solid-state glucose-asparagine Maillard reaction were simultaneously evidenced by this one-step DSC-FTIR microspectroscopy. The color changed from white to yellow-brown to dark brown, and appearance of new IR peaks confirmed the formation of Maillard reaction products.

Cheng et al. accidentally found that several new peaks at 3478,3345 and $1618 \mathrm{~cm}^{-1}$ were gradually increased their intensities from 60 to $78^{\circ} \mathrm{C}$ and then decreased with heating temperature in the threedimensional contour profile of $\mathrm{MCP} \mathrm{HCl} \mathrm{H}_{2} \mathrm{O}$ embedded in $\mathrm{KBr}$ pellet via determination with DSC-FTIR microspectroscopy (Fig. 9). However, there were no any new peaks found in the threedimensional contour profile of $\mathrm{MCP} \mathrm{HCl} \mathrm{H}_{2} \mathrm{O}$ embedded in $\mathrm{KCl}$ pellet [166]. These new IR peaks formed had been confirmed, due to the ion-exchange reaction occurred between $\mathrm{MCP} \mathrm{HCl}$ $\mathrm{H}_{2} \mathrm{O}$ and $\mathrm{KBr}$. The possible mechanism of this ion-exchange reaction might be attributed to the occurrence between the $\mathrm{HCl}$ salt of $\mathrm{MCP} \mathrm{H}_{2} \mathrm{O}$ and a $\mathrm{KBr}$ matrix by heating to yield a mixture of $\mathrm{HCl}$ and $\mathrm{HBr}$ salts of the MCP sample in the presence of hydrated water. The crystal hydrate played an important role to improve this ion-exchange reaction between $\mathrm{MCP} \mathrm{HCl}$ and $\mathrm{KBr}$. However, no ion-exchange reaction occurred between $\mathrm{MCP} \mathrm{HCl}$ $\mathrm{H}_{2} \mathrm{O}$ and $\mathrm{KCl}$ or between $150{ }^{\circ} \mathrm{C}$-preheated MCP $\mathrm{HCl}$ and $\mathrm{KBr}$. This solid-state ion-exchange reaction was only detected by this powerful DSC-FTIR microspectroscopy than other conventional methods.

In order to prevent the advanced glycation end products (AGEs) formation, the DSC-FTIR combined system as an accelerated method was also attempted to simultaneously determine the thermal-dependent conformational changes of human serum albumin (HSA) in the HSA-ribose mixture and also examined the onset of the structural transformation from $\alpha$-helix to $\beta$-sheet structures with or without AGEs inhibitors used [167]. The results clearly indicated that native HSA had an onset temperature at $96{ }^{\circ} \mathrm{C}$ for the irreversible thermal-induced structural transition from $\alpha$-helices to $\beta$-sheets; whereas HSA-ribose mixture exhibited its onset temperature near at $78{ }^{\circ} \mathrm{C}$ due to the early occurrence of ribosylation (Fig. 10). However, this onset temperature for the $\alpha$-helix to $\beta$-sheet transition was gradually changed from $78^{\circ} \mathrm{C}$ to $96^{\circ} \mathrm{C}$ by adding the amount of sodium diclofenac or inositol, which was closed to that of the onset temperature of native HSA, implying that the thermal-induced
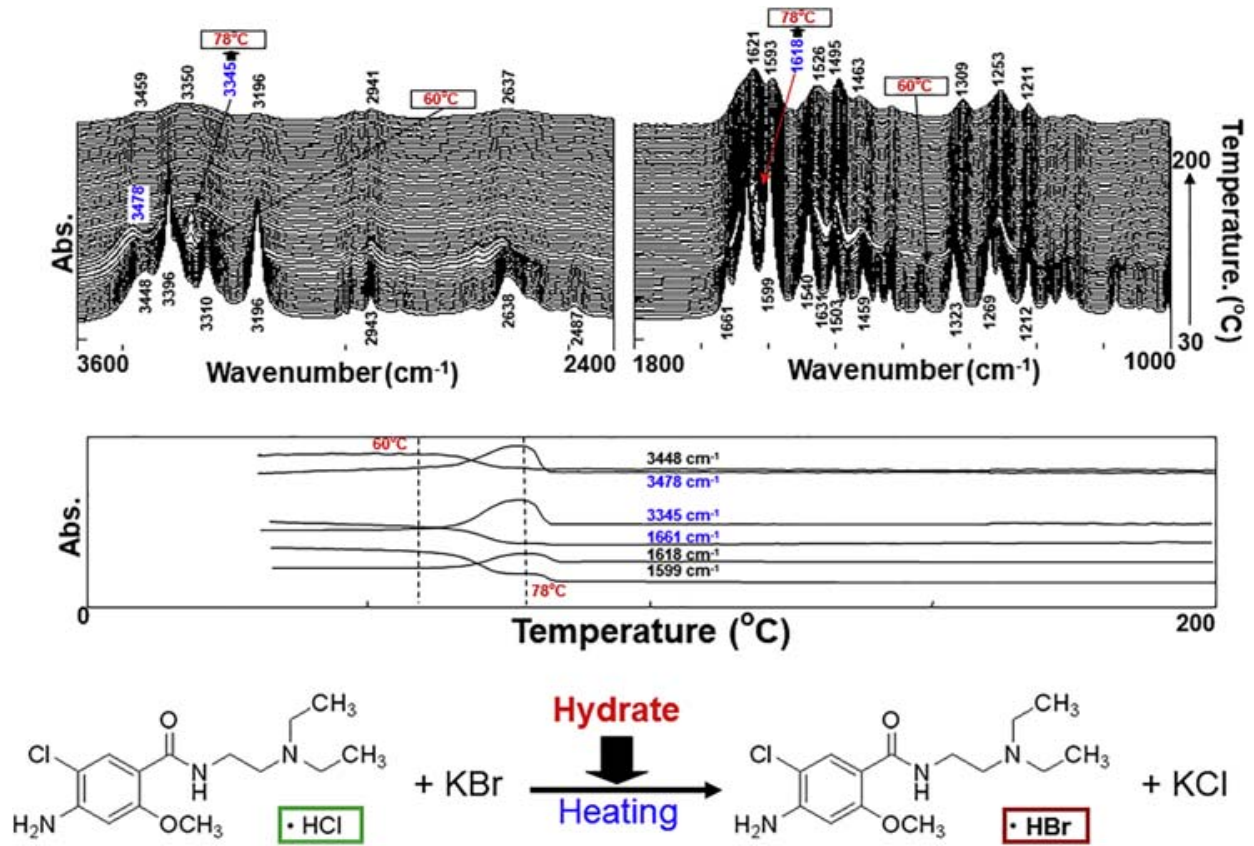

Fig. 9. Three-dimensional FTIR spectral plots and the thermally dependent changes in IR spectra of several specific peaks of metoclopramide hydrochloride monohydrate $\left(\mathrm{MCP} \mathrm{HCl} \mathrm{H} \mathrm{H}_{2} \mathrm{O}\right.$ ) prepared in the $\mathrm{KBr}$ pellet and its pathway of thermally-induced ion-exchange reaction [Modified, with permission from Ref. [166]]. 


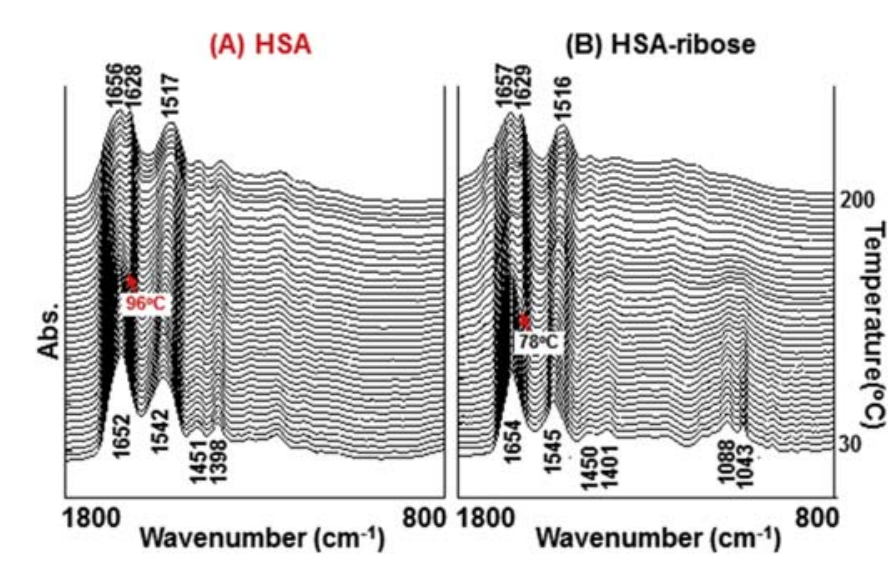

(C) Onset temperature from $\alpha$-helix to $\beta$-sheet

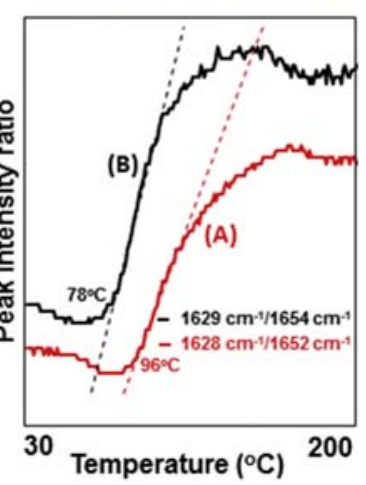

Fig. 10. Thermal-dependent FTIR spectral changes of native human serum albumin (HSA) (A) and HSA-ribose mixture (B), and the onset for conformational changes from $\alpha$-helix to $\beta$-sheet (C). [Modified, with permission from Ref. [167]].

conformational transition from $\alpha$-helix to $\beta$-sheet for HSA in the HSA-ribose mixture was effectively prevented by adding AGEs inhibitors (sodium diclofenac or inositol). This unique DSC-FTIR combined system could be a useful tool to quickly screen and evaluate the glycation-induced conformational changes of proteins in a one-step process.

\subsubsection{Solid-state real-time cocrystal screening and formation}

The characterization of an API is one of the most important stages in the preformulation development of a drug product. Unfortunately, not all of APIs can have ideal properties for their use as a pharmaceutical drug. Since more poorly water-soluble drug candidates are becoming increasingly popular in the drug development pipeline, many pharmaceutical technologies have been applied to enhance the dissolution and bioavailability of poorly water-soluble drugs [168-171], in which pharmaceutical cocrystals have recently gained increasing interest in the pharmaceutical industry [172-175]. Pharmaceutical cocrystals may provide a lot of desired physicochemical properties and patentability without altering the pharmacological properties, thus cocrystals have recently entered the scope of drug development within the supramolecular chemistry community $[172,176,177]$. With the advent of new regulatory guidance on pharmaceutical cocrystals from US FDA and EMA, pharmaceutical cocrystal as a promising drug candidate has become one of developing targets in the pharmaceutical industry [178-182].

There are many traditional processes and analytical techniques used for the preparation and identification of pharmaceutical cocrystals, however, these operations take considerable time to screen and prepare the cocrystals [172-177,183-187]. Here,
Lin and colleagues had first and successfully used this unique DSC-FTIR microspectroscopic approach to simultaneously and directly screen and detect pharmaceutical cocrystal formation in the following systems such as indomethacin-saccharin, indomethacin-nicotinamide, carbamazepine-glutaricacid, metaxalone-succinic-acid and piroxicamsaccharin [188-199]. This powerful one-step DSCFTIR combined technique provides an easy and direct method for one-step screening and qualitative detection of cocrystal formation in real time.

Indomethacin (IMC)-saccharin (SAC) cocrystal formation as an example [188,189,194,199], Fig. 11 shows the DSC curves and FTIR spectra of each component, physical mixture and solvent-evaporated sample of IMC and SAC. It clearly indicates that two endothermic peaks at 163 and $229^{\circ} \mathrm{C}$ were observed in the DSC curves; both peaks might be attributed to the melting points of IMC and SAC, respectively. On the other hand, the solvent-evaporated sample showed an endothermic peak near at $184{ }^{\circ} \mathrm{C}$, which was close to the melting point of IMC-SAC cocrystals at $182.6-184.2{ }^{\circ} \mathrm{C}$ respectively reported by Basavoju et al. and Padrela et al. [200,201]. The FTIR spectra of this solvent-evaporated sample is also displayed in Fig. 11, in which four unique FTIR peaks at 1734, 1714, 1682 and $1317 \mathrm{~cm}^{-1}$ clearly appeared. The first three FTIR peaks were similar to that of the IR positions of IMC-SAC cocrystals [202], implying that the solvent-evaporated IMC-SAC sample was recognized as a cocrystal. It is interesting to note that these four unique FTIR peaks $\left(1736,1718,1684,1319 \mathrm{~cm}^{-1}\right)$ were also directly evidenced from the thermaldependent three-dimensional FTIR spectral contour plot of the physical IMC-SAC mixture determined by a simultaneous DSC-FTIR combined technique after temperature above $154{ }^{\circ} \mathrm{C}$. The 


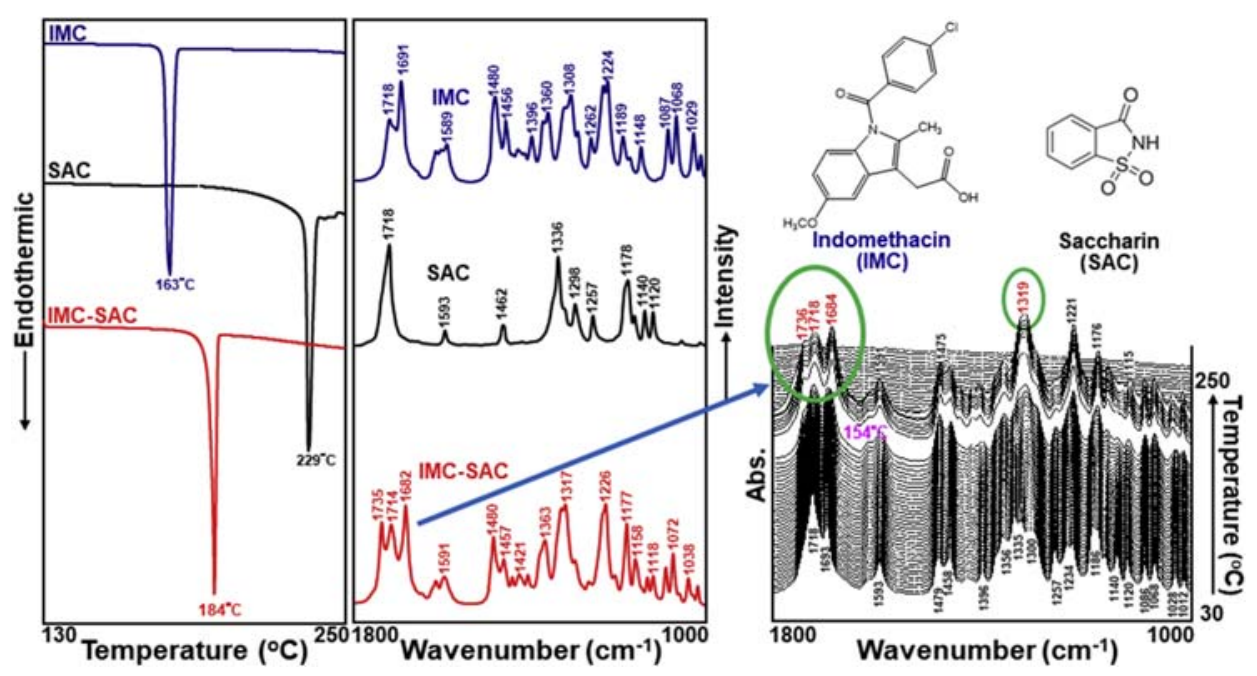

Fig. 11. The DSC curves and FTIR spectra of indomethacin (IMC), saccharin (SAC), and solvent-evaporated sample of IMC-SAC, as well as thermaldependent 3D FTIR spectral plot of the physical mixture of IMC-SAC [Modified, with permission from Refs. [189,194]].

appearance of these new IR peaks was due to cocrystal formation between IMC and SAC by hydrogen bonding [200-202]. This implies that this powerful DSC-FTIR microspectroscopic system providing the spectroscopic and thermodynamic information can easily, directly and simultaneously produce, screen and detect the IMC-SAC cocrystal formation in real time.

The other indomethacin-nicotinamide cocrystals, carbamazepine-glutaric-acid cocrystals, metaxalone-succinic-acid cocrystals and piroxicamsaccharin cocrystals exhibited similar behavior and can be directly obtained by this one-step simultaneous DSC-FTIR combined technique $[188,190-193$, 195-199].

\section{Conclusions}

In the recent years, solid-state chemistry of drugs is of growing importance in the pharmaceutical industry for developing the useful API and stable dosage forms [3-5], in which advanced solid-state analytical approaches play a critical role in pharmaceutical process control to detect and ensure the maximum quantity of an API in dosage forms $[28,29]$. Although many analytical techniques have been respectively used, the hyphenated analytical techniques have received ever-increasing attention in recent years as a special means to solve complex analytical problems in drug analysis [81-85]. The hyphenated technique is the combination or the coupling of the different analytical techniques. There are many advantages for hyphenated technique, such as shorter analysis time, higher degree of automation, higher sample throughput, better reproducibility, reduction of contamination, enhanced combined selectivity and higher degree of information $[44,83,203]$.

Among various hyphenated techniques for pharmaceutical analysis, a combination of DSC and FTIR is a very useful technique for monitoring structural changes of sample under thermal treatment [91-93]. This unique DSC-FTIR combined technique gives spectroscopic and thermodynamic information of samples in the heating process. DSC measures the exothermic and endothermic responses of the samples, while the FTIR analysis observes their structural changes in chemical and physical properties. This powerful DSC-FTIR combined system has been considerably applied to quickly investigate the thermal-induced structural changes and stability of foods, polymers, pharmaceuticals, excipients, and cocrystal formation [99,110-120,130-134,147-155, 163-167,188-199].

In this review article, a series of DSC-FTIR microspectroscopic studies had been clearly introduced in the rapid solid-state analysis of pharmaceuticals, polymers and excipients including (1) intramolecular condensation of pharmaceutical polymers, (2) intramolecular cyclization of drugs and sweetener, (3) polymorphic transformation of drugs and excipients, (4) drug-polymer (excipient) interaction, (5) fast cocrystal screening and formation. This powerful one-step DSC-FTIR combined technique provides an easy and direct method for one-step screening and qualitative detection of drug stability in real time (Fig. 12). In Fig. 12, trehalose dihydrate as a representative example for quick DSC-FTIR microspectroscopic study. An IR peak intensity at $1687 \mathrm{~cm}^{-1}$ corresponded to the 


\section{DSC-FTIR microspectroscopy}

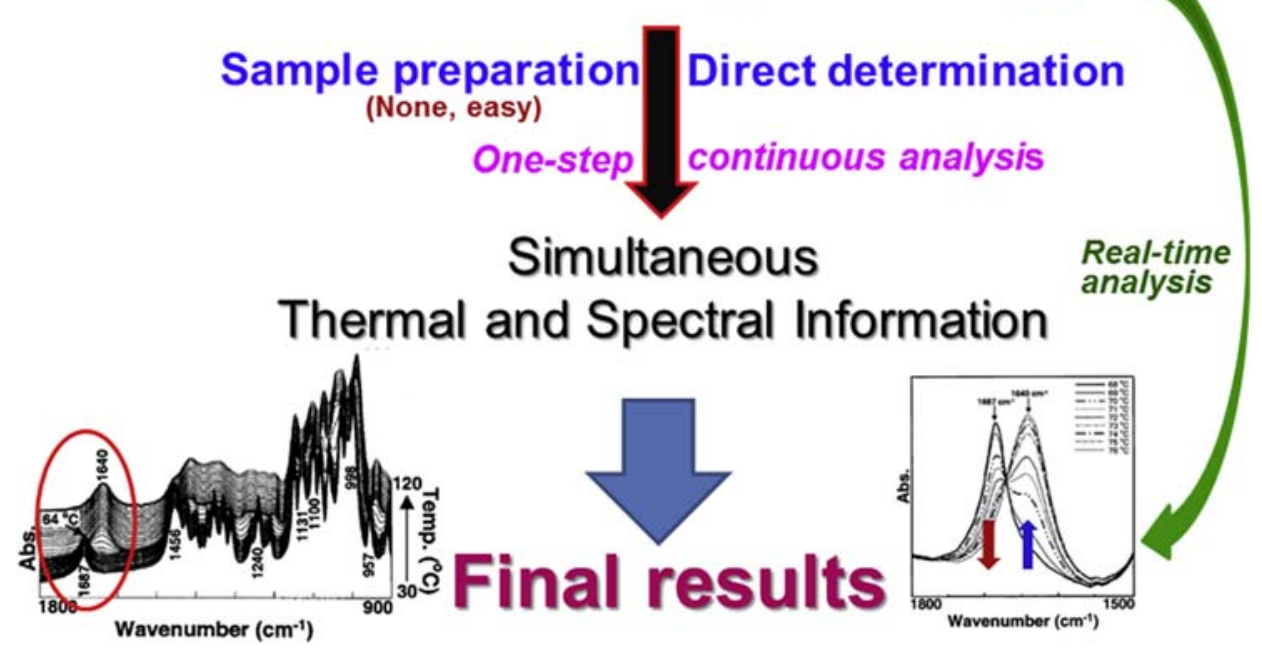

Fig. 12. The schematic flowchart of one-step simultaneous DSC-FTIR microspectroscopic analysis [Modified, with permission from Ref. [154]].

bending vibration mode of the solid-like water in trehalose dihydrate decreased sharply at $64{ }^{\circ} \mathrm{C}$. Simultaneously, another IR peak intensity at $1640 \mathrm{~cm}^{-1}$ due to the bending of liquid water quickly appeared and remained constant after $64{ }^{\circ} \mathrm{C}$ (left). This transitional temperature reflected the thermal-dependent transformation from solidlike water to liquid water in the trehalose dihydrate structure in the process of dehydration. A declining peak at $1687 \mathrm{~cm}^{-1}$ and a rising peak at $1640 \mathrm{~cm}^{-1}$ were only observed simultaneously from the DSC-FTIR microspectroscopic study in real time (right) [154].

In the near future, the hyphenated analytical technique will become an extremely versatile tool in pharmaceutical analysis by combining several analytical methods with automation and highthroughput (HT) analysis. Such hyphenation can enable simultaneous separation, identification, qualification and quantification of pharmaceutical components. Different hyphenated systems may be applied to solve many sophisticated analytical problems in various fields [82,85,92,204]. In the future mission, an integrated approach to ensuring sustainable development of HT analytical architecture and system can be introduced by an innovative technology, advanced equipment and new methodology with high-performance artificial intelligence (AI) systems to produce more accurate and reliable hyphenated instruments and measurements for pharmaceutical researchers in the pharmaceutical investigations and drug analysis [205-207].

\section{Acknowledgments}

I would like to express my profound gratitude to all research colleagues for their contributions in the DSC-FTIR microspectroscopic studies and also thanks the Ministry of Science and Technology (MOST), Taiwan, for research funding support in several studies (NSC-95-2320-B-075-002-MY2; NSC100-2320-B-264-001-MY3; MOST 103-2320-B-264002-MY2.)

\section{Funding}

A series of works were partially supported by Ministry of Science and Technology (MOST), Taiwan.

\section{Conflict of interest}

The author declares that there is no conflict of interest.

\section{References}

[1] ICH Guidelines. https://www.ich.org/page/qualityguidelines.

[2] Pramod K, Tahir MA, Charoo NA, Ansari SH, Ali J. Pharmaceutical product development: a quality by design approach. Int J Pharm Investig 2016;6:129-38.

[3] Jones TM. Preformulation studies. In: Tovey GD, editor. Pharmaceutical formulation: the science and technology of dosage forms. RSC Pub.; 2018. p. 1-41.

[4] Chaurasia G. A review on pharmaceutical preformulation studies in formulation and development of new drug molecules. Int J Pharma Sci Res 2016;7:2313-20.

[5] Byrn SR, Zografi G, Chen XS. Solid-state properties and pharmaceutical development. In: Byrn SR, Zografi G, Chen XS, editors. Solid-state properties of pharmaceutical materials. John Wiley \& Sons Inc.; 2017. p. 1-21. 
[6] Ticehurst MD, Marziano I. Integration of active pharmaceutical ingredient solid form selection and particle engineering into drug product design. J Pharm Pharmacol 2015; 67:782-802.

[7] Hlinak AJ, Kuriyan K, Morris KR, Reklaitis GV, Basu PK. Understanding critical material properties for solid dosage form design. J Pharm Innov 2006;1:12-7.

[8] Charoo NA. Critical excipient attributes relevant to solid dosage formulation manufacturing. J Pharm Innov 2020;15: 163-81.

[9] Leane M, Pitt K, Reynolds G. Manufacturing Classification System (MCS) Working Group. A proposal for a drug product manufacturing classification system (MCS) for oral solid dosage forms. Pharmaceut Dev Technol 2015;20: $12-21$.

[10] Morris KR, Griesser UJ, Eckhardt CJ, Stowell JG. Theoretical approaches to physical transformations of active pharmaceutical ingredients during manufacturing process. Adv Drug Deliv Rev 2001;48:91-114.

[11] HOrter D, Dressman JB. Influence of physicochemical properties on dissolution of drugs in the gastrointestinal tract. Adv Drug Deliv Rev 2001;46:75-87.

[12] Vippagunta SR, Brittain HG, Grant DJW. Crystalline solids. Adv Drug Deliv Rev 2001;48:3-36.

[13] ICH/FDA Guidance for industry. Q11 Development and manufacture of drug substances. 2012.

[14] Saluja V, Sekhon BS. The regulation of pharmaceutical excipients. J Excipients Food Chem 2013;4:95-106.

[15] Brittain HG, Bogdanowich SJ, Bugay DE, DeVincentis J, Lewen G, Newman AW. Physical characterization of pharmaceutical solids. Pharm Res (N Y) 1991;8:963-73.

[16] Suryanarayanan R, Byrn SR. Characterization of the solid state. Adv Drug Deliv Rev 2001;48:1-136.

[17] Storey RA, Ymén I, editors. Solid state characterization of pharmaceuticals. Wiley-Blackwell; 2011.

[18] Law D, Zhou D. Solid-state characterization and techniques. In: Qiu Y, Chen Y, Zhang GGZ, Yu L, Mantri RV, editors. Developing solid oral dosage forms: pharmaceutical theory and practice. 2 Ed. Academic Press; 2017. p. $59-84$.

[19] Brittain HG. Characterization of pharmaceutical compounds in the solid state. In: Ahuja S, Scypinski S, editors. Handbook of modern pharmaceutical analysis. Academic Press; 2001. p. 11-58.

[20] Vogt FG, Williams GR. Advanced approaches to effective solid-state analysis: $\mathrm{X}$-ray diffraction, vibrational spectroscopy, and solid-state NMR. Am Pharmaceut Rev 2010;13: 58-65.

[21] Chieng N, Rades T, Aaltonen J. An overview of recent studies on the analysis of pharmaceutical polymorphs. J Pharmaceut Biomed Anal 2011;55:618-44.

[22] Qiao Y, Qiao R, He Y, Shi C, Liu Y, Hao H, et al. Instrumental analytical techniques for the characterization of crystals in pharmaceutics and foods. Cryst Growth Des 2017;17:6138-48.

[23] Rantanen J, Khinast J. The future of pharmaceutical manufacturing sciences. J Pharmacol Sci 2015;104:3612-38.

[24] ICH Topic Q 1 A (R2). Stability testing of new drug substances and products. 2003.

[25] Huynh-Ba K, Dong MW. Stability studies and testing of pharmaceuticals: an overview. LC-GC N Am 2020;38: 325-36.

[26] Bharate SS, Bharate SB, Bajaj AN. Interactions and incompatibilities of pharmaceutical excipients with active pharmaceutical ingredients: a comprehensive review. J Excipients Food Chem 2010;1(3):3-26.

[27] Gupta KR, Pounikar AR, Umekar MJ. Drug excipient compatibility testing protocols and charaterization: a review. Asian J Chem Sci 2019;6(3):1-22.

[28] Bhusnure OG, Gholve SB, Nitin K, Giram PS, Gaikwad VM, Rajmane TM. Advanced approaches in solid-state analysis of pharmaceuticals. Int J Pharm Pharmaceut Res 2015;5(1):1-29.
[29] Newman AW, Byrn SR. Solid-state analysis of the active pharmaceutical ingredient in drug products. Drug Discov Today 2003;8:898-905.

[30] Newman A, Wenslow R. Solid form changes during drug development: good, bad, and ugly case studies. AAPS Open 2016;2:2.

[31] World Health Organization. Quality assurance of pharmaceuticals: a compendium of Guidelines and related materials. Good manufacturing practices and inspection. 2nd ed., vol. 2. Geneva: World Health Organization; 2007.

[32] Lionberger RA, Lee SL, Lee L, Raw A, Lawrence X, Yu LX. Quality by design: concepts for ANDAs. AAPS J 2008;10: 268-76.

[33] Lu J, Rohani S. Polymorphism and crystallization of active pharmaceutical ingredients (APIs). Curr Med Chem 2009; 16:884-905.

[34] Doelker E. Crystalline modifications and polymorphism changes during drug manufacture. Ann Pharm Fr 2002;60: 161-76.

[35] Baviskar SR, Patil SH. Solid phase transformation considerations during process development and manufacture of solid oral dosage forms-A review. Int J PharmTech Res 2014;6:1963-9.

[36] Bauer J, Spanton S, Henry R, Quick J, Dziki W, Porter W, et al. Ritonavir: an extraordinary example of conformational polymorphism. Pharm Res (N Y) 2001;18:859-66.

[37] Censi R, Di Martino P. Polymorph impact on the bioavailability and stability of poorly soluble drugs. Molecules 2015 20:18759-76.

[38] Gaisford S, Kett V, Haines P. Principles of thermal analysis and calorimetry. $2^{\text {nd }}$ ed. RSC Press; 2016.

[39] Müllertz A, Perrie Y, Rades T. Analytical techniques in the pharmaceutical sciences. CRS Press; 2016.

[40] Craig DQM, Reading M. Thermal analysis of pharmaceuticals. Taylor \& Francis; 2006

[41] Stodghill SP. Thermal analysis - a review of techniques and applications in the pharmaceutical sciences. Am Pharmaceut Rev 2010;13(2):29-36.

[42] Monajjemzadeh F, Ghaderi F. Thermal analysis methods in pharmaceutical quality control. J Mol Pharm Org Process Res 2015;3(1):e121.

[43] Gabbott P. Principles and applications of thermal analysis. Blackwell Pub; 2007.

[44] Lin SY. An overview of advanced hyphenated techniques for simultaneous analysis and characterization of polymeric materials. Crit Rev Solid State Mater Sci 2016;41: 482-530.

[45] Stieger N, Aucamp ME, Zhang SW, De Villiers MM. Hotstage optical microscopy as an analytical tool to understand solid-state changes in pharmaceutical materials. Am Pharmaceut Rev 2012;15(3):32-6.

[46] Kumar A, Singh P, Nanda A. Hot stage microscopy and its applications in pharmaceutical characterization. Appl Microsc 2020;50. article 12.

[47] Hashimoto K, Badarla VR, Kawai A, Ideguchi T. Complementary vibrational spectroscopy. Nat Commun 2019;10: 4411.

[48] Bunaciu A, Aboul-Enein H, Hoang VD, editors. Vibrational spectroscopy applications in biomedical. Pharmaceutical and food sciences. Elsevier; 2020.

[49] Muro CK, Doty KC, Bueno J, Halámková L, Lednev IK. Vibrational spectroscopy: recent developments to revolutionize forensic science. Anal Chem 2015;87:306-27.

[50] Rohman A, Windarsih A, Lukitaningsih E, Rafi M, Betania K, Fadzillah NA. The use of FTIR and Raman spectroscopy in combination with chemometrics for analysis of biomolecules in biomedical fluids: a review. Biomed Spectrosc Imag 2019;8:55-71.

[51] Wartewig S, Neubert RH. Pharmaceutical applications of Mid-IR and Raman spectroscopy. Adv Drug Deliv Rev 2005; 57:1144-70. 
[52] Aaltonen J, Gordon KC, Strachan CJ, Rades T. Perspectives in the use of spectroscopy to characterize pharmaceutical solids. Int J Pharm 2008;364:159-69.

[53] Heinz A, Strachan CJ, Gordon KC, Rades T. Analysis of solidstate transformations of pharmaceutical compounds using vibrational spectroscopy. J Pharm Pharmacol 2009;61:971-88.

[54] Deidda R, Sacré PY, Clavaud M, Coïc L, Avohou H, Hubert $\mathrm{P}$, et al. Vibrational spectroscopy in analysis of pharmaceuticals:Critical review of innovative portable and handheld NIR and Raman spectrophotometers. Trends Anal Chem 2019;114:251-9.

[55] Bunaciu AA, Aboul-Enein HY. Vibrational spectroscopy applications in DrugAnalysis. In: Lindon JC, Tranter GE, Koppenaal DW, editors. Encyclopedia of spectroscopy and spectrometry. 3rd ed. Elsevier; 2017. p. 575-81.

[56] Bunaciu AA, Aboul-Enein HY. Adulterated drug analysis using FTIR spectroscopy. Appl Spectrosc Rev 2020. http:// dx.doi.org/10.1080/05704928.2020.1811717.

[57] Morisseau KM, Rhodes CT. Pharmaceutical uses of nearinfrared spectroscopy. Drug Dev Ind Pharm 1995;21: 1071-90.

[58] Franklin EB. Theory and principles of near infrared spectroscopy. Spectrosc Eur 2002;14:12-8.

[59] Gabriele R. Near-infrared spectroscopy and imaging: basic principles and pharmaceutical applications. Adv Drug Deliv Rev 2005;57:1109-43.

[60] Jamrógiewicz M. Application of the near-infrared spectroscopy in the pharmaceutical technology. J Pharmaceut Biomed Anal 2012;66:1-10.

[61] Strachan CJ, Taday PF, Newnham DA, Gordon KC, Zeitler JA, Pepper M, et al. Using terahertz pulsed spectroscopy to quantify pharmaceutical polymorphism and crystallinity. J Pharmacol Sci 2005;94:837-46.

[62] Zeitler JA, Taday PF, Newnham DA, Pepper M, Gordon KC, Rades T. Terahertz pulsed spectroscopy and imaging in the pharmaceutical setting-A review. J Pharm Pharmacol 2007; 59:209-23.

[63] Shen YC. Terahertz pulsed spectroscopy and imaging for pharmaceutical applications: a review. Int J Pharm 2011;417: $48-60$.

[64] Haaser M, Gordon KC, Strachan CJ, Rades T. Terahertz pulsed imaging as an advanced characterisation tool for film coatings-A review. Int J Pharm 2013;457:510-20.

[65] Bawuah P, Markl D, Farrell D, Evans M, Portieri A, Anderson A, et al. Terahertz-based porosity measurement of pharmaceutical tablets: a tutorial. J Infrared, Millim Terahertz Waves 2020;41:450-69.

[66] Alves-Lima D, Song J, Li X, Portieri A, Shen Y, Zeitler JA, et al. Review of Terahertz pulsed imaging for pharmaceutical film coating analysis. Sensors 2020;20(5):1441.

[67] Zhang R, Liu S, Jin H, Luo Y, Zheng Z, Gao F, et al. Noninvasive electromagnetic wave sensing of glucose. Sensors 2019;19(5):1151.

[68] Das R, Eaqub A, Hamid A, Bee S. Current applications of xray powder diffraction-A review. Rev Adv Mater Sci 2014; 38:95-109.

[69] Bunaciu AA, Udristioiu EG, Aboul-Enein HY. X-Ray diffraction: instrumentation and applications. Crit Rev Anal Chem 2015;45:289-99.

[70] Randall C, Rocco W, Ricou P. XRD in pharmaceutical analysis: a versatile tool for problem-solving. Am Pharmaceut Rev 2010;13(6):52-9.

[71] Brittain HG. X-ray diffraction III: pharmaceutical applications. Spectroscopy 2001;16(7):14-8

[72] Anwar J. Pharmaceuticals: Design and development of drug delivery systems. In: Chung FH, Smith DK, editors. Industrial applications of X-ray diffraction. Marcel Dekker; 2000. p. 539-53.

[73] Widjonarko NE. Introduction to advanced X-ray diffraction techniques for polymeric thin films. Coatings 2016;6:54.

[74] https://www.physics.upenn.edu/ heiney/datasqueeze/ basics.html.
[75] Aitipamula S, Vangala VR. X-Ray crystallography and its role in understanding the physicochemical properties of pharmaceutical cocrystals. J Indian Inst Sci 2017;97: 227-43.

[76] Bond A. Pharmaceutical crystallography: a guide to structure and analysis. RSC Pub; 2019.

[77] Thakral NK, Zanon RL, Kelly RC, Thakral S. Applications of powder X-ray diffraction in small molecule pharmaceuticals: achievements and aspirations. J Pharmacol Sci 2018; 107:2969-82.

[78] Caira MR. Current applications of powder x-ray diffraction in drug discovery and development. Am Pharmaceut Rev 2014;17:54.

[79] Litteer B, Beckers D. Increasing application of X-ray powder diffraction in the pharmaceutical industry. Am Lab 2005;37: 22-4.

[80] Ivanisevic I, McClurg RB, Schields PJ. Uses of X-ray powder diffraction in the pharmaceutical industry. In: Gad SC, editor. Pharmaceutical sciences encyclopedia: drug discovery, development, and manufacturing. John Wiley \& Sons; 2010. p. 1-42.

[81] Patel KN, Patel JK, Patel MP, Rajput GC, Patel HA. Introduction to hyphenated techniques and their applications in pharmacy. Pharma Methods 2010;1(1):2-13.

[82] Singh S, Handa T, Narayanam M, Sahu A, Junwal M, Shah RP. A critical review on the use of modern sophisticated hyphenated tools in the characterization of impurities and degradation products. J Pharmaceut Biomed Anal 2012; 69:148-73.

[83] Joshi RR, Gupta KR, Patil SS. Hyphenated technique-A boon to analytical world. Int J Pharma Sci Res 2012;3: 4184-91.

[84] Usman Md, Badgujar SR, Shaikh TY. Hyphenated techniques of drug analysis. Scholars Acad J Pharm 2017;6: 263-72.

[85] Sarker SD, Nahar L. Hyphenated techniques and their applications in natural products analysis. Methods Mol Biol 2012;864:301-40.

[86] Phalke PL, Kavade S. Review on hyphenated techniques. Int J Chem Stud 2013;1:157-65.

[87] Mulgund SV, Chitre TS, Mallade PS, Bariwal JB, Jain KS. Hyphenated techniques in analytical world. Indian J Pharm Edu Res 2008;42:393-401.

[88] Ermer J, Vogel M. Applications of hyphenated LC-MS techniques in pharmaceutical analysis. Biomed Chromatogr 2000;14:373-83.

[89] Pan C, Liu F, Motto M. Identification of pharmaceutical impurities in formulated dosage forms. J Pharmacol Sci 2011;100:1228-59.

[90] Mirabella FM. Simultaneous differential scanning calorimetry (DSC) and infrared spectroscopy using an infrared microsampling accessory (IRMA) and FT-IR. Appl Spectrosc 1986;40:417-20.

[91] Johnson DJ, Compton DAC, Canale PL. Applications of simultaneous DSC/FTIR analysis. Thermochim Acta 1992; 195:5-20.

[92] Giron D. Applications of thermal analysis and coupled techniques in pharmaceutical industry. J Therm Anal Calorim 2002;68:335-57.

[93] Schindler A, Neumann G, Rager A, Füglein E, Blumm J, Denner T. A novel direct coupling of simultaneous thermal analysis (STA) and Fourier transform-infrared (FT-IR) spectroscopy. J Therm Anal Calorim 2013;113:1091-102.

[94] Spragg R. Combining FTIR microspectroscopy with differential scanning calorimetry. Analusis 2000;28:64-7.

[95] Materazzi S. Thermogravimetry-infrared spectroscopy (TGFTIR) coupled analysis. Appl Spectrosc Rev 1997;32: 385-404.

[96] Pasch H. Hyphenated separation techniques for complex polymers. Polym Chem 2013;4:2628-50.

[97] Wolfender JL, Queiroz EF, Hostettmann K. The importance of hyphenated techniques in discovery of new lead 
compounds from nature. Expet Opin Drug Discov 2006;1: 237-60.

[98] Pan C, Liu F, Ji Q, Wang W, Drinkwater D, Vivilecchia R. The use of LC/MS, GC/MS, and LC/NMR hyphenated techniques to identify a drug degradation product in pharmaceutical development. J Pharmaceut Biomed Anal 2006;40:581-90.

[99] Lin SY, Wang SL. Advances in simultaneous DSC-FTIR microspectroscopy for rapid solid-state chemical stability studies: some dipeptide drugs as examples. Adv Drug Deliv Rev 2012;64:461-78.

[100] Deokate U, Gorde AM. Forced degradation and stability testing: strategies and analytical perspectives. Int J Pharmaceut Sci Rev Res 2014;42:242-50.

[101] Tanna S, Ogwu J, Lawson G. Hyphenated mass spectrometry techniques for assessing medication adherence: advantages, challenges, clinical applications and future perspectives. Clin Chem Lab Med 2020;58:643-63.

[102] Menard N, Menard K. Hyphenated techniques in thermal analysis. In: Meyers RA, editor. Encyclopedia of analytical chemistry: applications, theory and instrumentation. John Wiley \& Sons; 2018. p. 1-10.

[103] Menard KP, Spragg R, Johnson G, Sellman C. Hyphenation: the next step in thermal analysis. Am Lab 2010;42:21-3.

[104] Leyva-Porras C, Cruz-Alcantar P, Espinosa-Solís V, Martínez-Guerra E, Balderrama C, Martínez IC, et al. Application of differential scanning calorimetry (DSC) and modulated differential scanning calorimetry (MDSC) in food and drug industries. Polymers 2019;12(1):5.

[105] Koberstein JT, Gancarz I, Clarke TC. The effects of morphological transitions on hydrogen bonding in polyurethanes: preliminary results of simultaneous DSCFTIR experiments. J Polym Sci B Polym Phys 1986;24: 2487-98.

[106] Dugan G, McCarty JD, Friant RJ. The application of combined differential scanning calorimetry-mass spectrometry (DSC-MS) to the study of thermal and oxidative decompositions. In: Porter RS, Johnson JF, editors. Analytical calorimetry. Springer; 1970. p. 417-27.

[107] Yoshida H, Kinoshita R, Teramoto Y. Development of the simultaneous thermal analysis/X-ray scattering measurement system. Thermochim Acta 1995;264:173-83.

[108] Keller G, Lavigne F, Forte L, Andrieux K, Dahim M, Loisel C, et al. DSC and X-Ray diffraction coupling. J Therm Anal Calorim 1998;51:783-91.

[109] Degamber B, Winter D, Tetlow J, Teagle M, Fernando GF. Simultaneous DSC/FTIRS/TMA. Meas Sci Technol 2004;15: L5-10.

[110] Jasco Co. Introduction of new DLATGS detector for IRT5000/7000 infrared microscope. https://www.jasco.pl/wpcontent/uploads/2013/01/260MT0239_E.pdf.

[111] Lin SY, Lin CC. One-step real-time food quality analysis by simultaneous DSC-FTIR microspectroscopy. Crit Rev Food Sci Nutr 2016;56:292-305.

[112] Lin SY, Tsay WJ, Chen YL, Lee CJ. Application of a new micro FTIR/DSC technique to the study of curing kinetics of silicone elastomer. J Contr Release 1994;31:277-82.

[113] Lin SY, Liao CM, Hsiue GH. A reflectance FTIR/DSC microspectroscopic study of nonisothermal kinetics of anhydride formation in Eudragit L-100 films. Polym Degrad Stabil 1995;47:299-303.

[114] Lin SY, Liao CM, Hsiue GH. Thermal-dependent anhydride formation of Eudragit L-100 films determined by reflectance FTIR/DSC microspectroscopy. Polymer 1995;36: 3239-41.

[115] Lin SY, Liao CM, Hsiue GH. Isothermal kinetics of anhydride formation in Eudragit L-100 films determined by reflectance FTIR/DSC microspectroscopy. Polymer 1996;37: 269-73.

[116] Lin SY, Yu HL, Li MJ. Formation of six-membered cyclic anhydrides by thermally induced intramolecular ester condensation in Eudragit E film. Polymer 1999;40: 3589-93.
[117] Lin SY, Yu HL. Thermal stability of methacrylic acid copolymers of Eudragits L, S and L $30 \mathrm{D}$ and the acrylic acid polymer of carbopol. J Polym Sci Polym Chem 1999;37: 2061-7.

[118] Lin SY, Yu HL. Microscopic Fourier transform infrared/ differential scanning calorimetry system used to study the different thermal behaviors of polymethacrylate copolymers of Eudragits RS, RL, E 30D or E. J Appl Polym Sci 2000;78:829-35.

[119] Lin SY, Cheng WT, Wei YS, Lin HL. DSC-FTIR microspectroscopy used to investigate the thermal-induced intramolecular cyclic anhydride formation between Eudragit E and PVA copolymer. Polym J 2011;43:577-80.

[120] Lin SY, Laio CM, Liang RC. Use of microscopic FT-IR/DSC combined system for the study of glass transition temperature of polymers. Polym J 1995;27:201-4.

[121] Steinberg SM, Bada JL. Peptide decomposition in the neutral $\mathrm{pH}$ region via the formation of diketopiperazines. J Org Chem 1983;48:2295-8.

[122] Lai MC, Topp EM. Solid-state chemical stability of proteins and peptides. J Pharmacol Sci 1999;88:489-500.

[123] Chang LL, Pikal MJ. Mechanisms of protein stabilization in the solid state. J Pharmacol Sci 2009;98:2886-908.

[124] Manning MC, Chou DK, Murphy BM, Payne RW, Katayama DS. Stability of protein pharmaceuticals: an update. Pharm Res (N Y) 2010;27:544-75.

[125] Zapadka KL, Becher FJ, Gomes Dos Santos AL, Jackson SE. Factors affecting the physical stability (aggregation) of peptide therapeutics. Interface Focus 2017;7(6):20170030.

[126] Leung SS, Grant DJW. Solid-state stability studies of model dipeptides: aspartame and aspartylphenylalanine. J Pharmacol Sci 1997;86:64-71.

[127] Toporisic R, Mlakar A, Hvala J, Prislan I, Zupancic-Kralj L. Identification of new impurities of enalapril maleate on oxidation in the presence of magnesium monoperoxyphthalate. J Pharmaceut Biomed Anal 2010;52:294-9.

[128] Hailu SA, Bogner RH. Effect of the $\mathrm{pH}$ grade of silicates on chemical stability of coground amorphous quinapril hydrochloride and its stabilization using $\mathrm{pH}$-modifiers. J Pharmacol Sci 2009;98:3358-72.

[129] Shafiq S, Shakeel F, Khar RK. Enhanced stability of ramipril in nanoemulsion containing cremophor-EL: a technical note. AAPS Pharm Sci Tech 2008;9:1097-101.

[130] Wang SL, Lin SY, Chen TF. Thermal-dependent dehydration process and intramolecular cyclization of lisinopril dihydrate in the solid state. Chem Pharm Bull 2000;48: 1890-3.

[131] Wang SL, Lin SY, Chen TF. Reaction kinetics of solid-state cyclization of enalapril maleate investigated by isothermal FT-IR microscopic system. Chem Pharm Bull 2001;49:402-6.

[132] Lin SY, Wang SL, Chen TF, Hu TC. Intramolecular cyclization of diketopiperazine formation in solid-state enalapril maleate studied by thermal FT-IR microscopic system. Eur J Pharm Biopharm 2002;54:249-54.

[133] Lin SY, Cheng YD. Simultaneous formation and detection of the reaction products of solid-state aspartame sweeteener by FT-IR/DSCmicroscopic system. Food Addit Contam 2000;17:821-7.

[134] Cheng YD, Lin SY. Isothermal FT-IR microspectrosopic studies on the stability kinetics of solid-state intramolecular cyclization of aspartame sweetener. J Agric Food Chem 2000;48:631-5.

[135] Widjaja E, Lim GK, Cho PS, Tan S. Multivariate data analysis as a tool to investigate the reaction kinetics of intramolecular cyclization of enalapril maleate studied by isothermal and non-isothermal FT-IR microscopy. Eur J Pharmaceut Sci 2007;32:349-436.

[136] Tan WJ, Widjaja E. Multivariate chemometric approach to thermal solid-state FT-IR monitoring of pharmaceutical drug compound. J Pharmacol Sci 2008;97:3379-87.

[137] Widjaja E, Tan WJ. Kinetics of lisinopril intramolecular cyclization in solid phase monitored by Fourier transform infrared microscopy. Appl Spectrosc 2008;62:889-94. 
[138] Hsu CH, Lin SY. Rapid examination of the kinetic process of intramolecular lactamization of gabapentin using DSCFTIR. Thermochim Acta 2009;486:5-10.

[139] Singhal D, Curatolo W. Drug polymorphism and dosage form design: a practical perspective. Adv Drug Deliv Rev 2004;56(3):335-47.

[140] Zhou Y, Wang J, Xiao Y, Wang T, Huang X. The effects of polymorphism on physicochemical properties and pharmacodynamics of solid drugs. Curr Pharmaceut Des 2018; 24:2375-82.

[141] Ainurofiq A, Dinda KE, Pangestika MW, Himawati U, Wardhani WD, Sipahutar YT. The effect of polymorphism on active pharmaceutical ingredients: a review. Int J Res Pharm Sci 2020;11:1621-30.

[142] Karaźniewicz-Łada M, Bąba K, Dolatowski F, Dobrowolska A, Rakicka M. The polymorphism of statins and its effect on their physicochemical properties. Polim Med 2018;48(2):77-82.

[143] Blandizzi C, Viscomi GC, Scarpignato C. Impact of crystal polymorphism on the systemic bioavailability of rifaximin, an antibiotic acting locally in the gastrointestinal tract, in healthy volunteers. Drug Des Dev Ther 2015;9:1-11.

[144] Zhang GGZ, Law D, Schmitt EA, Qiu Y. Phase transformation considerations during process development and manufacture of solid oral dosage forms. Adv Drug Deliv Rev 2004;56:371-90.

[145] Saifee M, Inamdar N, Dhamecha DL, Rathi AA. Drug polymorphism: a review. Int J Health Res 2009;2:291-306.

[146] Higashi K, Ueda K, Moribe K. Recent progress of structural study of polymorphic pharmaceutical drugs. Adv Drug Deliv Rev 2017;117:71-85.

[147] Wang SL, Lin SY, Wei YS. Transformation of metastable forms of acetaminophen studied by thermal Fourier transform infrared (FT-IR) microspectroscopy. Chem Pharm Bull 2002;50:153-6.

[148] Lin SY, Wang SL, Cheng YD. Thermally induced structural changes of acetaminophen in phase transition between the solid and liquid states monitored by combination analysis of FT-IR/DSC microscopic system. J Phys Chem Solid 2000; 61:1889-93.

[149] Lin SY, Cheng WT, Wang SL. Thermodynamic and kinetic characterization of polymorphic transformation of famotidine during grinding. Int J Pharm 2006;318:86-91.

[150] Wang SL, Wong YC, Cheng WT, Lin SY. A continuous process for solid-state dehydration, amorphization and recrystallization of metoclopramide HCL monohydrate studied by simultaneous DSC-FTIR microspectroscopy. J Therm Anal Calorim 2011;104:261-4.

[151] Lin SY. Molecular perspectives on solid-state phase transformation and chemical reactivity of drugs: metoclopramide as an example. Drug Discov Today 2015;20:209-22.

[152] Kao CU, Huang HH, Huang YT, Lin LH, Lin SY. Thermoanalytical and spectroscopic studies on amorphization and phase transition of amorphous indomethacin prepared by two melt-cooling processes. Sci Lett J 2015;4:148.

[153] Lin HL, Chi YT, Huang YT, Kao CY, Lin SY. DSC-FTIR combined approaches used to simultaneously prepare/ determine the amorphous solid dispersions of indomethacin/Soluplus in real-time. EC Pharm Sci 2015;2:183-93.

[154] Lin SY, Chien JL. In vitro simulation of solid-solid dehydration, rehydration and solidification of trehalose dihydrate using thermal and vibrational spectroscopic techniques. Pharm Res (N Y) 2003;20:1926-31.

[155] Cheng WT, Lin SY. Processes of dehydration and rehydration of raffinose pentahydrate investigated by thermal analysis and FT-IR/DSC microscopic system. Carbohydr Polym 2006;64:212-7.

[156] Greco K, Bogner R. Crystallization of amorphous indomethacin during dissolution: effect of processing and annealing. Mol Pharm 2010;7:1406-18.

[157] Lin SY, Cheng WT. The use of hot-stage microscopy and thermal micro-Raman spectroscopy in the study of phase transformation of metoclopramide $\mathrm{HCl}$ monohydrate. J Raman Spectrosc 2012;43:1166-70.

[158] Lin SY, Cheng WT, Wang SL. Thermal micro-Raman spectroscopic study of polymorphic transformation of famotidine under different compression pressures. J Raman Spectrosc 2007;38:39-43.

[159] Cheng WT, Lin SY, Li MJ. Raman microspectroscopic mapping or thermal system used to investigate millinginduced solid-state conversion of famotidine polymorphs. J Raman Spectrosc 2007;38:1595-601.

[160] Wang SL, Lin SY, Chen TF, Chuang CH. Solid-state transcis isomerization of captopril determined by thermal Fourier transform infrared (FT-IR) microspectroscopy. J Pharmacol Sci 2001;90:1034-9.

[161] Serajuddin AT, Thakur AB, Ghoshal RN, Fakes MG, Ranadive SA, Morris KR, et al. Selection of solid dosage form composition through drug-excipient compatibility testing. J Pharmacol Sci 1999;88:696-704.

[162] Patel JP, Ahir K, Patel V, Manami L, Patel C. Drug excipient compatibility studies: first step for dosage form development. Pharma Innov J 2015;4(5):14-20.

[163] Lin SY, Liao CM, Hsiue GH, Liang RC. Study of theophylline-Eudragit L mixture by using a combined system of microscopic Fourier transform infrared spectroscopy and differential scanning calorimetry. Thermochim Acta 1995; 245:153-66.

[164] Wang SL, Lin SY, Chen TF, Cheng WT. Eudragit E accelerated the diketopiperazine (DKP) formation of enalapril maleate determined by thermal FTIR microspectroscopic technique. Pharm Res (N Y) 2004;21:2127-32.

[165] Hwang DF, Hsieh TF, Lin SY. One-step simultaneous differential scanning calorimetry-FTIR microspectroscopy to quickly detect continuous pathways in the solid-state glucose/asparagine Maillard reaction. J AOAC Int 2016;96: 1362-4.

[166] Cheng WT, Wang SL, Lin SY. Thermal FT-IR microspectroscopy for rapid detection of solid-state ion-exchange reaction between metoclopramide $\mathrm{HCl}$ monohydrate and potassium bromide. Analyst 2011;136:1036-40.

[167] Huang YT, Liao HF, Wang SL, Lin SY. Thermal Fourier transform infrared technique quickly detects an early onset of glycation-induced conformational changes of human serum albumin. Pharm Anal Acta 2016;7:512.

[168] Williams HD, Trevaskis NL, Charman SA, Shanker RM, Charman WN, Pouton CW, et al. Strategies to address low drug solubility in discovery and development. Pharmacol Rev 2013;65:315-499.

[169] Kawabata Y, Wada K, Nakatani M, Yamada S, Onoue S. Formulation design for poorly water-soluble drugs based on biopharmaceutics classification system: basic approaches and practical applications. Int J Pharm 2011;420: $1-10$.

[170] Zhang X, Xing H, Zhao Y, Ma Z. Pharmaceutical dispersion techniques for dissolution and bioavailability enhancement of poorly water-soluble drugs. Pharmaceutics 2018;23(3):74. 10.

[171] Varshosaz J, Ghassami E, Ahmadipour S. Crystal engineering for enhanced solubility and bioavailability of poorly soluble drugs. Curr Pharmaceut Des 2018;24: 2473-96.

[172] Schultheiss N, Newman A. Pharmaceutical cocrystals and their physicochemical properties. Cryst Growth Des 2009;9: 2950-67.

[173] Karagianni A, Malamatari M, Kachrimanis K. Pharmaceutical cocrystals: new solid phase modification approaches for the formulation of APIs. Pharmaceutics 2018;10(1):18.

[174] Karimi-Jafari M, Padrela L, Walker GM, Croker DM. Creating cocrystals: a review of pharmaceutical cocrystal preparation routes and applications. Cryst Growth Des 2018;18:6370-87.

[175] Panzade PS, Shendarkar GR. Pharmaceutical cocrystal: a game changing approach for the administration of old 
drugs in new crystalline form. Drug Dev Ind Pharm 2020;46: 1559-68.

[176] Trask AV. An overview of pharmaceutical cocrystals as intellectual property. Mol Pharm 2017;4:301-9.

[177] Jayram P, Sudheer P. Pharmaceutical co-crystals: a systematic review. Int J Pharm Invest 2020;10(3):246-52.

[178] US Food and Drug Administration (FDA). Guidance for industry regulatory classification of pharmaceutical Cocrystals. 2018.

[179] European Medicines Agency (EMA). Reflection paper on the use of cocrystals of active substances in medicinal products. 2015.

[180] Gadade DD, Pekamwar SS. Pharmaceutical cocrystals: regulatory and strategic aspects, design and development. Adv Pharm Bull 2016;6:479-94.

[181] Izutsu KI, Koide T, Takata N, Ikeda Y, Ono M, Inoue M, et al. Characterization and quality control of pharmaceutical cocrystals. Chem Pharm Bull 2016;64:1421-30.

[182] Peltonen L. Practical guidelines for the characterization and quality control of pure drug nanoparticles and nano-cocrystals in the pharmaceutical industry. Adv Drug Deliv Rev 2018;131:101-15.

[183] Kojima T, Tsutsumi S, Yamamoto K, Ikeda Y, Moriwaki T. High-throughput cocrystal slurry screening by use of in situ Raman microscopy and multi-well plate. Int J Pharm 2010; 399:52-9.

[184] Lu E, Rodríguez-Hornedo N, Suryanarayanan R. A rapid thermal method for cocrystal screening. Cryst Eng Comm 2008;10:665-8.

[185] Zalte AG, Saudagar RB. Advanced techniques in preparation of cocrystals. Int J Sci Progr Res 2015;12:32-5.

[186] Douroumis D, Ross SA, Nokhodchi A. Advanced methodologies for cocrystal synthesis. Adv Drug Deliv Rev 2017; 117:178-95.

[187] Pindelska E, Sokal A, Kolodziejski W. Pharmaceutical cocrystals, salts and polymorphs: advanced characterization techniques. Adv Drug Deliv Rev 2017;117:111-46.

[188] Wu TK, Lin SY, Lin HL, Huang YT. Simultaneous DSCFTIR microspectroscopy used to screen and detect the cocrystal formation in real time. Bioorg Med Chem Lett 2011; 21:3148-51.

[189] Zhang GC, Lin HL, Lin SY. Thermal analysis and FTIR spectral curve-fitting investigation of formation mechanism and stability of indomethacin-saccharin cocrystals via solidstate grinding process. J Pharmaceut Biomed Anal 2012;66: 162-9.

[190] Hsu PC, Lin HL, Wang SL, Lin SY. Solid-state thermal behavior and stability studies of theophylline-citric acid cocrystals prepared by neat cogrinding or thermal treatment. J Solid State Chem 2012;192:238-45.

[191] Lin HL, Hsu PC, Lin SY. Theophylline-citric acid co-crystals easily induced by DSC-FTIR microspectroscopy or different storage conditions. Asian J Pharm Sci 2013;8:19-27.

[192] Lin HL, Wu TK, Lin SY. Screening and characterization of cocrystal formation of metaxalone with short-chain dicarboxylic acids induced by solvent-assisted grinding approach. Thermochim Acta 2014;575:313-21.

[193] Lin HL, Zhang GC, Huang YT, Lin SY. An investigation of indomethacin-nicotinamide cocrystal formation induced by thermal stress in the solid or liquid state. J Pharmacol Sci 2014;103:2386-95.

[194] Lin HL, Zhang GC, Lin SY. Real-time co-crystal screening and formation between indomethacin and saccharin via DSC analytical technique or DSC-FTIR microspectroscopy. J Therm Anal Calorim 2015;120:679-87.

[195] Lin SY, Lin HL, Hung RY, Huang YT, Kao CY. Effect of Povacoat or Soluplus on solid-state characterization of indomethacin-nicotinamide co-crystal formation. Pharm Anal Acta 2015;6:402.

[196] Lin HL, Huang YT, Lin SY. Spectroscopic and thermal approaches to investigate the formation mechanism of piroxicam-saccharin co-crystal induced by liquid-assisted grinding or thermal stress. J Therm Anal Calorim 2016;123: 2345-56.

[197] Lin SY, Lin HL, Chi YT, Hung RY, Huang YT, Hsieh WH, et al. Influence of Soluplus on solid-state properties and physical stability of indomethacin-saccharin co-crystal formation prepared by air-drying process. J Pharm Innov 2016; 11:109-19.

[198] Lin SY. Mechanochemical approaches to pharmaceutical cocrystal formation and stability analysis. Curr Pharmaceut Des 2016;22:5001-18.

[199] Lin SY. Simultaneous screening/detection of pharmaceutical co-crystals by one-step DSC-FTIR microspectroscopic technique. Drug Discov Today 2017;22:718-28.

[200] Basavoju S, Boström D, Velaga SP. Indomethacin-saccharin cocrystal: design, synthesis and preliminary pharmaceutical characterization. Pharm Res (N Y) 2008;25:530-41.

[201] Padrela L, Rodrigues MA, Velaga SP, Matos HA, de Azevedo EG. Formation of indomethacin-saccharin cocrystals using supercritical fluid technology. Eur J Pharmaceut Sci 2009;38:9-17.

[202] Ali HRH, Alhalaweh A, Mendes NFC, Ribeiro-Claro P, Velaga SP. Solid-state vibrational spectroscopic investigation of cocrystals and salt of indomethacin. Cryst Eng Comm 2012;14:6665-74.

[203] Taleuzzaman M, Gilani SJ. Brief on -Hyphenated methods of HPLC for determining the presence of solutes. Chron Pharm Sci 2017;1(1):35-42.

[204] Phalke P, Kavade S. Review on hyphenated techniques. Int J Chem Studies 2013;1:157-65.

[205] Badyal PN, Sharma C, Navdeep K, Shankar R, Pandey A Rawal RK. Analytical techniques in simultaneous estimation: an overview. Austin J Anal Pharm Chem 2015;2(2):1037.

[206] Kind T, Fiehn O. Hardware and software challenges for the near future: structure elucidation concepts via hyphenated chromatographic techniques. LC-GC N Am 2008;26(2): 176-87.

[207] Beccaria M, Cabooter D. Current developments in LC-MS for pharmaceutical analysis. Analyst 2020;145:1129-57. 